VALVILESS ASH REMOVAL FROM PRESSURIZED FLUIDRED-BED COMBUSTION SYSTEMS BY GRAVEL BUCKET

Final Repont

By

A. K. Henderson

W. B. Hauserman

Warch 1981

Work Pertormed Under Comtrect No. AC21-89MC25151

For

U.S. Department of Energy

Morgantown Energy Tcchnology Center

Morgantown, Weat Virglinia

Ey

Untweretty of North Dakota

Grand Forks, North Dakota 


\section{DISCLAIMER}

This repon wes prepared as an ecoount of work sponsored by an agency of the United States Government. Neither the United States Government nor any asency thereof. nor any of their employees, makes any warranty, express or implied, cr assumes any lepal liability of responsibility for the accuracy, completeness, or usefulness of any information, apparatus, product, of process discloced, or represents that its use would not infringe privately owned riehts. Reference herein to any specific commercial product, process, or service by trade neme. trademark, manufacturer, or otherwise does not necessarily constitute or imply its endorsement, recommendation, or favoring by the United States Government or any agency thereof. The views and opinions of authors expresced herein do not necescarily state or reflect those of the United Sutes Government or any agency thereot.

This report has been reproduced directly from the best available copy.

Available to DOE and DOE contractors from the Office of Scientific and Technical Information, P.O. Box 62, Oak Ridge, TN 37831; prices available from (615)576-8401, FTS 626-8401.

Available to the public from the National Technical Information Service, U.S. Department of Commerce, 5285 Port Royal Rd., Springfield, VA 22161. 


\title{
Valveless Ash Removal From Pressurized Fluidized-Bed Combustion Systems by Gravel Bucket
}

\author{
Final Report
}

\author{
A.K. Henderson \\ W.B. Hauserman
}

Work Performed Under Contract No.: DE-AC21-89MC25151

\author{
For \\ U.S. Department of Energy \\ Office of Fossil Energy \\ Morgantown Energy Technology Center \\ P.O. Box 880 \\ Morgantown, West Virginia 26507-0880 \\ University of North Dakota \\ Energy and Environmental Research Center \\ P.O. Box 8213 \\ University Station \\ Grand Forks, North Dakota 58202
}


LIST OF FIGURES ....................... 1

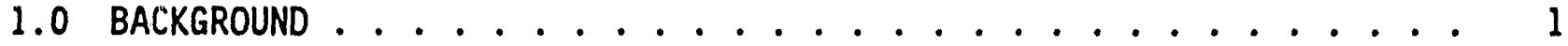

2.0 GOALS AND OBJECTIVES ................... 4

3.0 APPARATUS AND TESTING ............... 5

3.1 Cold Simulation ..................... 5

3.2 High-Pressure Testing . . . . . . . . . . . 7

4.0 RESULTS AND DISCUSSION .................. 8

4.1 Cold Simulation Results ................. 8

4.2 Mathematical Model ................. 10

4.3 High-Pressure Results .................. 10

4.4 Control system Concepts ................ 15

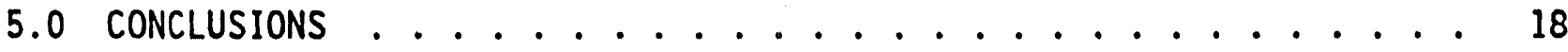

6.0 REFERENCES ..................... 20

APPENDIX A: Economic Comparison of a Gravel Bucket-Type Ash

Letdown Device With Conventional Lockhoppers for Pressurized

Fluid-Bed Combustion Systems 


\section{LIST OF FIGURES}

Eigures

Page

1 Packed beds at high flows .................. 3

2 Gravel bucket valveless ash removal system . . . . . . . . . . 4

3 Gravel bucket cold simulation apparatus . . . . . . . . 6

4 Gravel bucket high-pressure test apparatus . . . . . . . . . 9

5 Pressure drop data for $3 / 8^{n}$ lava rock . . . . . . . . . . . 11

6 Pressure drop data for 1/2" ceramic spheres . . . . . . . . . 11

7 Pressure drop data for $3 / 4 "$ ceramic spheres . . . . . . . . . 12

8 Pressure drop data for lava rock, where fluid mass velocity is based on the effective density of air and sand . . . . . . . . 12

9 Dependence of constant $C$ and exponent $b$ on packing particle

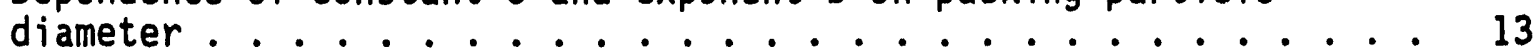

10 Pressure distribution for high-pressure test \#1 . . . . . . . 14

11 Pressure distribution for high-pressure test \#2 . . . . . . 16

12 Gravel bucket control system . . . . . . . . . . . . 17

13 Effect of packing particle diameter dP on pressure drop . . . . 19 


\section{VALVELESS ASH REMOVAL FROM PRESSURIZED FLUIDIZED-BED \\ COMBUSTION SYSTEMS BY GRAVEL BUCKET}

\subsection{BACKGROUND}

One of the problems inherent in a pressurized combustor is the withdrawal of solids from the high-pressure reactor vessel. Because full-scale pressurized fluidized-bed combustion (PFBC) technology is still in the developmental stage, it must rely on existing knowledge to deal with this problem, until new technologies can be developed. A conventional solids removal system consisting of valves and lockhoppers has a number of disadvantages. First, the solids flowing through a pressure letdown valve are extremely abrasive. A valve in such an environment will eventually wear to such an extent that the valve trim needs to be repaired or replaced. Not only is this a large maintenance expense, but the entire lockhopper must be taken out of service in order for repairs to be made. Secondly, a lockhopper removes solids in a batch mode, while the solids are produced continually. These difficulties have prompted the development of the gravel bucket as an alternative to valves and lockhoppers. The gravel bucket approach carries the ash with a flow of combustion air though a packed bed of inexpensive, coarsely crushed rock. The majority of the abrasive wear that would otherwise erode costly fabricated components instead erodes the rock, which can be replaced at low cost.

An earlier project tested a variant of the gravel bucket principle, in which an erosive, high-pressure slurry passes through a bed of crushed rock with. adjustable flow path and cross-sectional area(1). The concept was inspired by the valve erosion problems of coal liqueiaction plants. Valve erosion, incurred in getting either a slurry or gas-borne solid out of any pressurized coal conversion or combustion process, will be a major maintenance expense. This project focuses on the removal of solids from pressurized fluidized-bed combustion systems. It is hoped that a gravel bucket can offer an economic alternative to a lockhopper plus a pair of expensive block valves.

Three variations of the gravel bucket design were considered in the early stages of the project. The simplest was the downflow packed bed. The ashbearing gas flows downward through a column of coarsely crushed rock. Small, compact units would be possible, since the pressure drop would not be limited by the bed's weight. This variation was rejected because of the possibility that a fixed bed might become plugged with ash; however, plugging was not observed during the course of the present project or the original gravel bucket slurry valve project (2).

A second option under consideration was the reversible flow packed bed. In this configuration, flow is alternated between two packed beds, with the ash flowing through them in opposite directions, so that if either bed becomes plugged, permeability could be restored by reversing the flow direction. This would provide a manual, positive means of overcoming plugging, but it requires a flow reversal valve, which, if needed frequently, might prove to require replacement as often as the valves in a lockhopper system. The primary design basis for this study is to avoid a?l contact between the erosive ash stream and any precision manufactured surfice. 
The preferred design is the upward flow, reverse-packed bed. Ash-bearing gas flows upward through a bed of crushed rock, which is supported against an upper retaining plate when the pressure drop through the bed exceeds the bed's weight, and the superficial velocity exceeds the terminal settling velocity of the largest packing particles. Thus the pressure drop across the bed can greatly exceed the weight of the bed, enabling a small voiume of rock to provide the same pressure drop as a much larger fluidized bed held down by gravity. If the bed becomes completely plugged with ash, the flow stops, the aerodynamic forces supporting the bed decrease, and the bed collapses or expands downward in response to gravity, leieasing the impacted ash. This principle is illustrated in Figure 1, showing the effects of gradually increasing the velocity of the gas flow through a bed. The packed bed at the lefit becomes a fluidized bed when the pressure drop across the bed exceeds the bed weight. This stage is generally characterized by a rhythmic bouncing, or slugging of the bed particles, and if the particles are not of uniform size, the smallest particles migrate to the top of the bed. When the velocity exceeds the terminal settling velocity of these smallest particles, they rise to the top of the column where they are held in place by the upper retaining plate. As gas velocity increases, successively larger particles shift to the top of the column until the entire bed is reverse packed. The reverse fluidized bed at the right shows a plugged bed collapsing to release trapped ash.

When solids are added to the gas stream, the stages in Figure 1 occur at lower flow rates, and pressure drop is increased. The higher the solids loading in the gas, the shorter the bed needed to impart the necessary pressure drop. Literature on derse pneumatic transport suggests that solids loadings in excess of $80 \%$ are possible $(3)$, and loadings approaching this magnitude have been observed in this project.

A phenomenon similar to reverse fluidized-bed behavior has been observed in a slagging, fixed-bed gasifier $(4,5)$. A massive bed of coarsely crushed coal, partialiy piugged with fine dust generated by thermal and mechanical attrition, bridged in the upper portion of the gasifier. This occurred at pressure drops slightly below the weight of the bed, which was partly supported by wall friction. The bridged bed would periodically collapse, indicated by an abrupt decrease in pressure drop.

A conceptual schematic of a gravel bucket ash pressure letdown system is shown in Figure 2. While more complex than a lockhopper with two valves, its economic rationale is that the vessel will be smaller, and the only valves in the system will not be subjected to severe erosion, and thus amortized as long-term capital items. Based on operating data in the coal gasification industry, lockhopper valves are replaced frequently, adding a major maintenance cost to the total annualized operating cost. The key factor in a final economic comparison will be the cost and useful life of acceptable, "corventional" valves. The valves shown in Figure 2, while apparently violating the valveless claim of the device, are part of the crushed rock replacement system. Only the crushed rock used for bed packing will be subjected to the abrasive ash stream and will need to be replenished periodically. The frequency of rock replacement will depend on the abrasiveness of the ash and the hardness of the rock $(6)$. While not enough data exists to predict rock erosion rates, it is assumed that the interval will be on the order of days, 


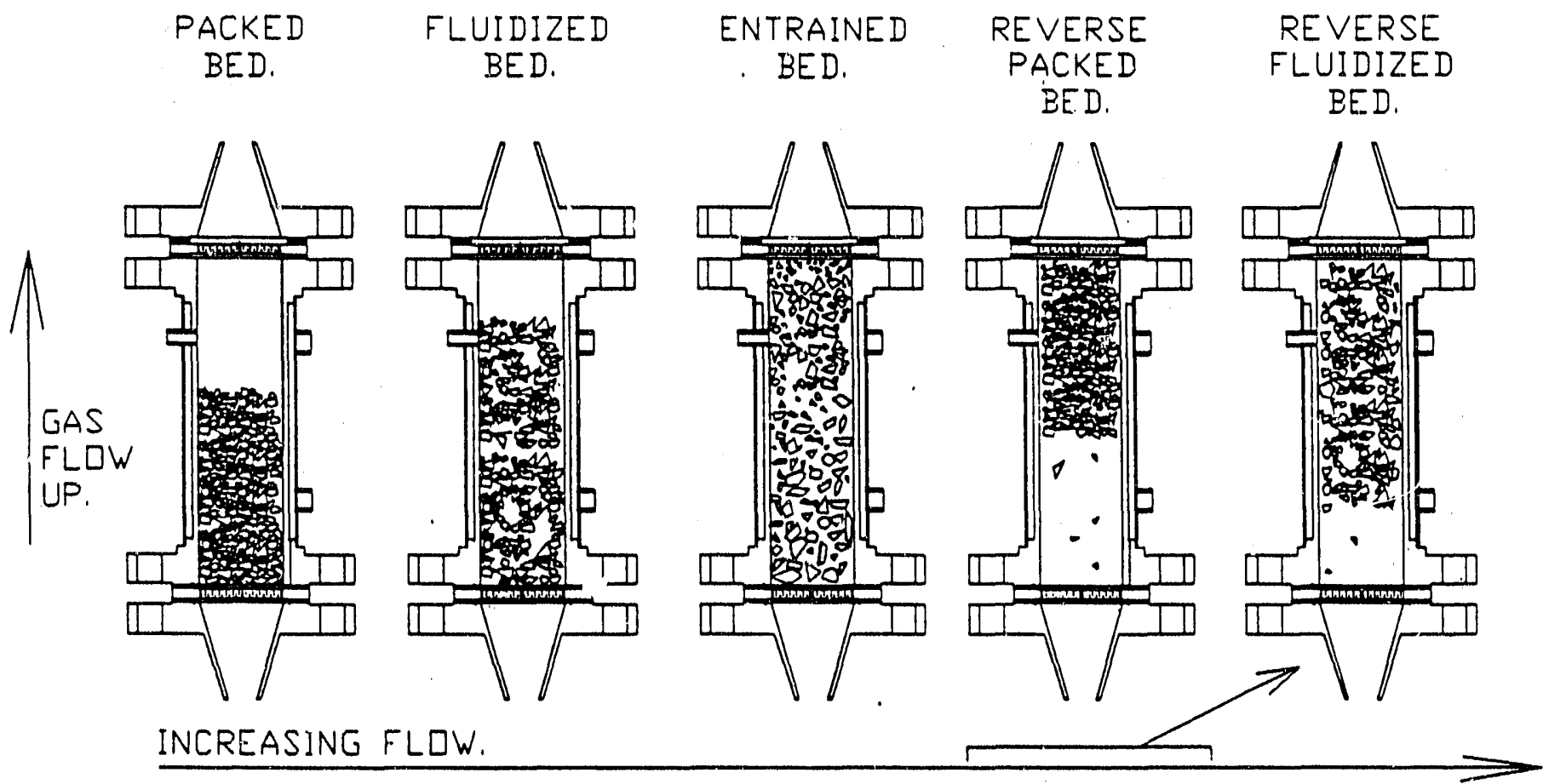

Figure 1. Packed beds at high flows.

weeks, or possibly months. The system will be designed to minimize the temperature of the valves involved. Lockhopper valves, on the other hand, are opened every few hours, or even more frequently, and are subject to very high temperatures. The number of valves in the rock replacement system depends, of course, on the number of sections into which the gravel bucket is divided. The reason for multiple sections is to facilitate reverse fluidization in the event of plugging, assuming that a relatively short bed will reverse-fluidize more readily than a deeper bed. The number of sections used will therefore depend on the tendency of the ash in question to plug.

The most similar current effort resembling this approach is that by Knowlton (7) in which a dense stream of hot ash is packed into and pushed through a length of pipe, with the pressure drop provided by the wail friction of the sliding ash and the small flow of gas through the ash. A similar concept, applicable to other processes, was investigated by Demeter in 1961 (8). These approaches offer greater simplicity than the concept proposed here, but contain no provision for freeing an impacted mass of material when it fails to acknowledge the design assumptions predicting its flow behavior. The greatest similarity to the proposed system is found in earlier work by Carlson in 1980 (9), in which the flow of an erosive slurry, as from a coal liquefaction process, through a bed of ceramic spheres was controlled by the introduction of a flashing liquid. This appears analogous to the proposed system of Figure 2 , in which control flows of air are introduced. 


\section{GRAVEL BUCKET ASH LETDOWN SYSTEM}
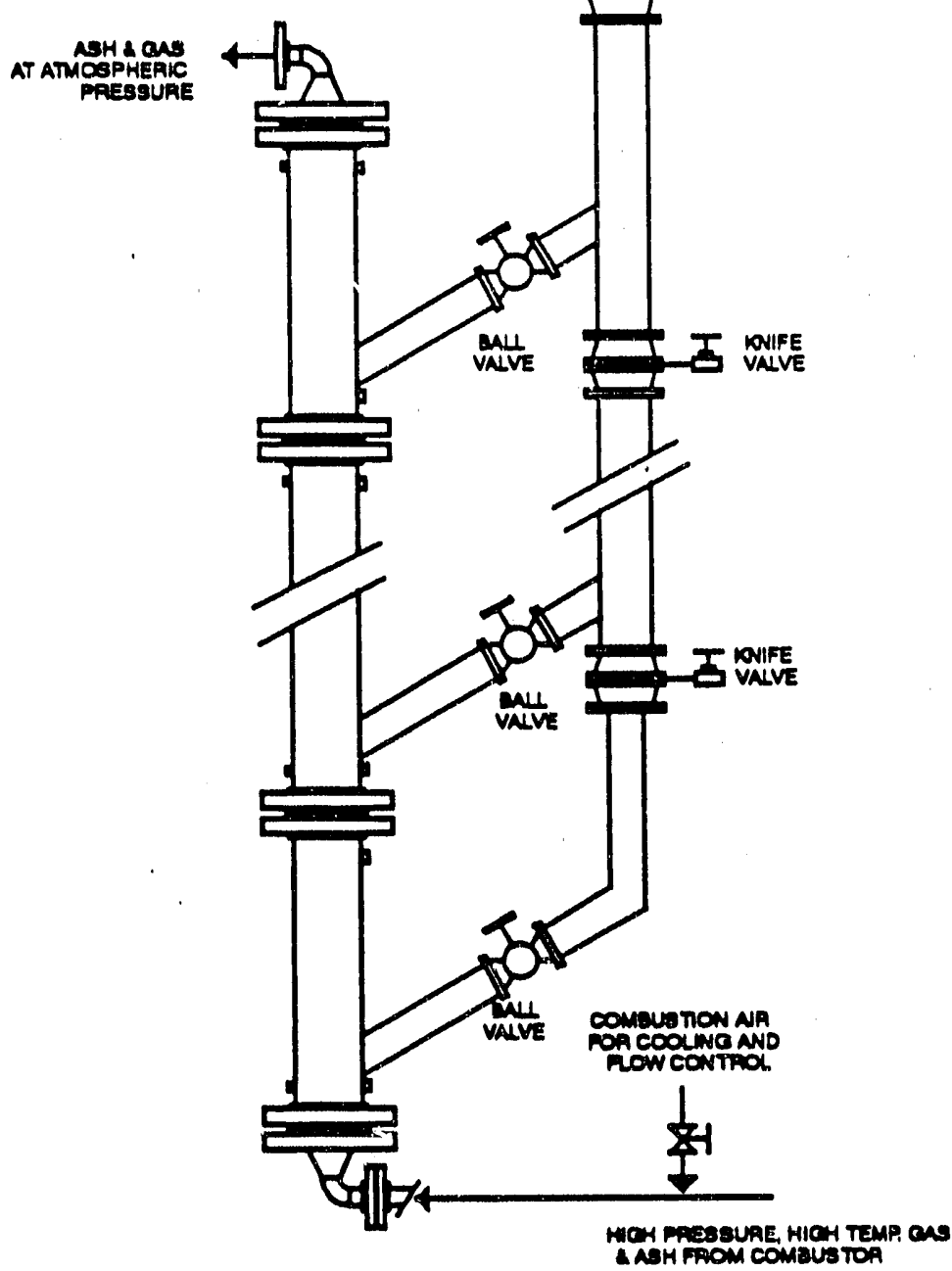

Figure 2. Gravel bucket valveless ash removal system.

\subsection{GOALS AND OBJECTIVES}

The objective of this project is to apply the gravel bucket pressure letdown concept to a stream of hot, gas-borne ash, under conditions similar to those found in a pressurized fluidized-bed combustor, where the sysiem pressure is dissipated across a packed or partially fluidized bed of coarsely crished rock. 
A second objective is to use the data collected during testing to develop a mathematical model which can be used to predict pressure drop in a gravel bucket device.

The final objective of the project is to develup an economic analysis comparing the cost of constructing and operating a gravel bucket with that of a lockhopper system. The results of this analysis will be submitted as a separate report.

\subsection{APPARATUS AND TESTING}

\subsection{Cold Simulation}

The experimental apparatus for the cold simulation studies is shown in Figure 3. It is a modification of EERC's cold flow, circlilating fluidized-bed simulation. Plexigias pipes were used to contain the bed, allowing for observation of bed behavior. Two different pipes were used, having diameters of 4 and 8 inches. These columns were filled with beds of various materials, with heights ranging from 11 inches to 29 inches, which was the full height of the culumn. Perforated plates at the top and bottom of the test section held the bed material in place. The venturi section immediately below the test section served to increase the velocity of the carrier air at the sand inlet, to ensure that the sand was carried upward with the air. The sand tank was pressurized to a level siightly higher than the upstream air pressure, allowing the sand to flow freely into the venturi section. Pressures ranged from 1 to $9.5 \mathrm{psig}$ at ambient temperature. For each new bed material or height, the air flow was gradually increased from a minimum of 50 to a maximum of 240 $\mathrm{ft}^{3} / \mathrm{min}$. At each flow rate, the upstream pressure, pressure drop across the bed, flow rate, and condition of the bed were recorded. The air flow rate was measured with an orifice plate located downstream of the test section. Several runs were made with air only, while the sand tank was being constructed. The same procedure was used with sand, except that three sets of readings were made at each fiow rate. The first readings were taken when the air flow was increased, without any sand in the stream. Then the valve at the bottom of the sand tank was opened and sand allowed to flow for about a minute, during which time pressures and flow rate were recorded. A stopwatch was used to record the time between opening and closing the valve. The sand was recovered in another column of clear plexiglas, so that the level of sand at each time interval could be measured and the volume of sand calculated. A third set of readings was taken after the sand valve was closed, before the air flow was increased.

Three different materials were used for the bed: ceramic spheres, limestone, and lava rock (6). Different sizes of ceramic spheres were used to determine the effect of bed particle size alone, since these materials were of relatively uniform shape and size (during sustained operation of a gravel bucket, it is expected that the bed material will tend to become sphericai as a result of tumbling action and abrasion from fine solids). Lava rock, sized to an average diameter of $3 / 8$ ", was selected to observe the possible effect of a significantly lower particle density. The limestone sample used consisted of very irregularly shaped particles and a large size distribution, with some 


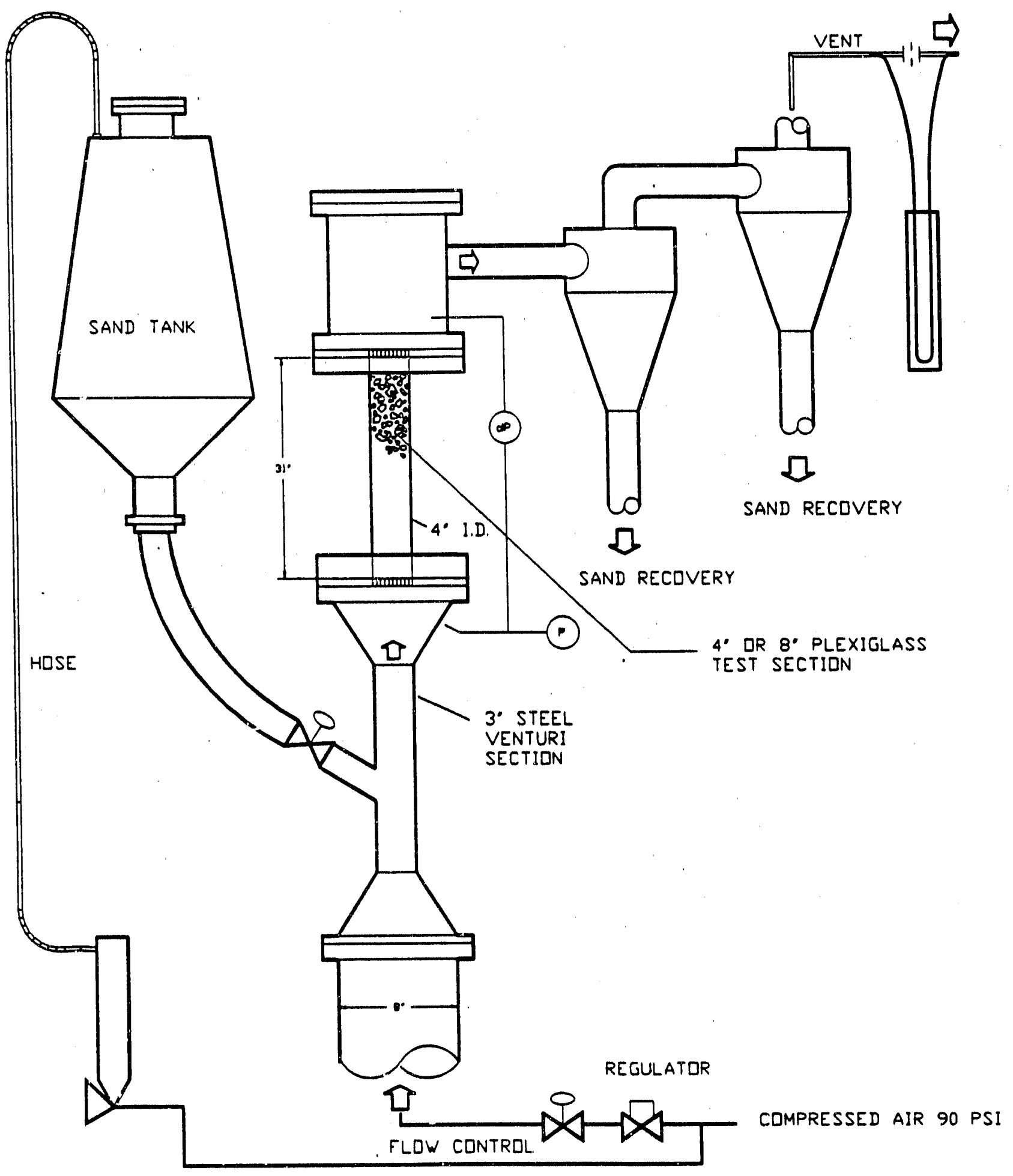

Figure 3. Gravei bucket cold simulation apparatus. 
individual particles over two inches long. This should most closely represent what might be used in a practical application. A gravel bucket design should utilize whatever rock is available at low cost, both in terms of delivery and preparation, so minimal crushing and sizing is desirable.

\subsection{High-Pressure Testing}

Originally, it was proposed that the gravei bucket would be tested in conjunction with EERC's pilot-scale PFBC system. Unfortunately, chanaes were made to the PFBC program which eliminated the construction of a pilot.-scale unit at this time.

A principal that should be emphasized is that the logical and practical way to test a proposed component for any large process system is to install the test unit, or a series of design variations thereof, in a full-scale, online plant, or at least a pilot-scale plant, operating under typical or representative conditions. This ensures that all project funds and efforts will be spent on component testing, according to the objectives of the project. Where no commercial or continuous pilot plant is in operation, as in the case of pressurized fluidized-bed combustion, simulation of realistic process conditions is often more tedious and costiy than actual design and testing of the component.

The best available simulation tool for the purpose of this project was EERC's gas turbine combustion simulator, which provides the same pressure and temperature and can simulate ash flow conditions. Use of the turbine simulator offered several advantages over the PFBC system for the purposes of this project. It allowed dedicated runs for testing the gravel bucket, providing desired pressures and temperatures that would have been impossible on the PFBC pilot unit, because of the substantial cost of operating the latter. The disadvantage of the turbine simulator was low ash flow rate capability. The ash feed system was a modification of an existing device. Funding limitations precluded the construction of a larger ash feeder.

The turbine simulation system was designed primarily to burn coal slurries in a gas turbine. It is capable of operating at pressures near 200 psig and tomperatures of $2000^{\circ} \mathrm{F}$. The turbine was recently fitted with a high-temperature, high-pressure cyclone to collect ash when the unit is run on coal-water slurry. A seal pot at the bottom of the cyclone will collect the coal ash.

The high-pressure gravel bucket consisted of five identical sections. Each section was four inches in diameter, two feet tall, and contained crushed rock to a depth of twenty inches. A length of horizontal pipe bolted to the bottom of the turbine cyclone carried air and ash from the turbine to the gravel bucket. A compressed air line was added to the bottom of the cyclone to provide cooling and ensure the air flow was great enough to carry ash through the gravel bucket; this proved to be unnecessary, since the air flow through the turbine was great enough to eliminate the need for additional air. Pressures and temperatures were measured at each section; that is, at approximately 24" intervals from the first distributor plate. Air flow rate was measured downstream of a high-pressure cyclone, which collected ash and fine 
bed material that passed through the distributor plates. A.11 data points were collected every thirty seconds with a Genesis data acquisition system. A schematic of the high-pressure test unit is shown in Figure 4.

To provide a stream of ash, a lockhopper with a rotating pocket valve was installed above the combustion zone; ash was fed inio the turbine at a rate of 3 pounds per hour. The ash used for this test was collected during a run on the EERC 2.25- $\mathrm{ft}^{2}$ bubbling fluidized-beu combustor. The gravel bucket ras fully water-jacketed to control temperatures, under the assumption that the turbine would be running on natural gas; however, the temperature of the air coming into the unit was controlled with the turbine's air preheater and a single water jacket on the horizontal piping from the turbine exit to the gravel bucket inlet.

The first series of cests were conducted with distributor plates separating each of the five sections, with each section containing roughly the same amount of rock. Then the intermediate plates were removed, creating a sing?e beed of rock 100 inches high. Runs 1 and 3 were conducted at ambient temperature. The temperature in Run 2 was increased using the turbine's air preivater. Temperatures in the turbine reached $800^{\circ} \mathrm{F}$, but the temperature in the gravel bucket was controlled with a water jacket on the piping between the turbine and the gravel bucket inlet.

\subsection{RESULTS AND DISCUSSION}

\subsection{Cold Simulation Results}

Cold simulation tests covered pressure drops of up to $10 \mathrm{psi}$ at air flow rates as high as $240 \mathrm{scfm}$, in 4- and 8-inch diameter plexiglas test sections for the bed materials described above. Single bed heights ranged from 11 to 29 inches; stacked beds in the 8-inch seicion were each 8 inches high.

The 29-inch beds filled the entire test section, so the beds remained packed at all flow conditions. For all other bed heights, the condition of the bed depended on the weight of the rick in the bed and the upstream pressure of the air flow. For example, the force of a 21-inch bed of lava rock in the four-inch-diameter column is $1.36 \mathrm{psi}$. When the air pressure exceeded the force of the bed, the bed particles rose to the top of the chamber. In the 21 -inch bed of lava rock, $60 \%$ of the bed material packed to the top of the chamber at 1.4 psi; $80 \%$ was packed at the top at 2.2 psi; and $90 \%$ was packed at the top at $3.6 \mathrm{psi}$. The percentage of lava rock that remained at the bottom of the chamber was fully fluidized. When sand was added to the air stream, both the upstream pressure and the fluid density increased, so the entile bed was reverse-packed at the top of the chamber.

In tests using a larger, heavier rock, such as limestone of $3 / 4^{\prime \prime}$ ceramic spheres, bed behavior was generally similar, although the addition of air was not always enough to raise the lower portion of the bed to the top. Two phencmena were observed in beds of larger particles that were not evident with lava rock or small ceramic spheres. First, the larger particles, particularly the irregularly shaped limestone particles, were much more likely to arrange 


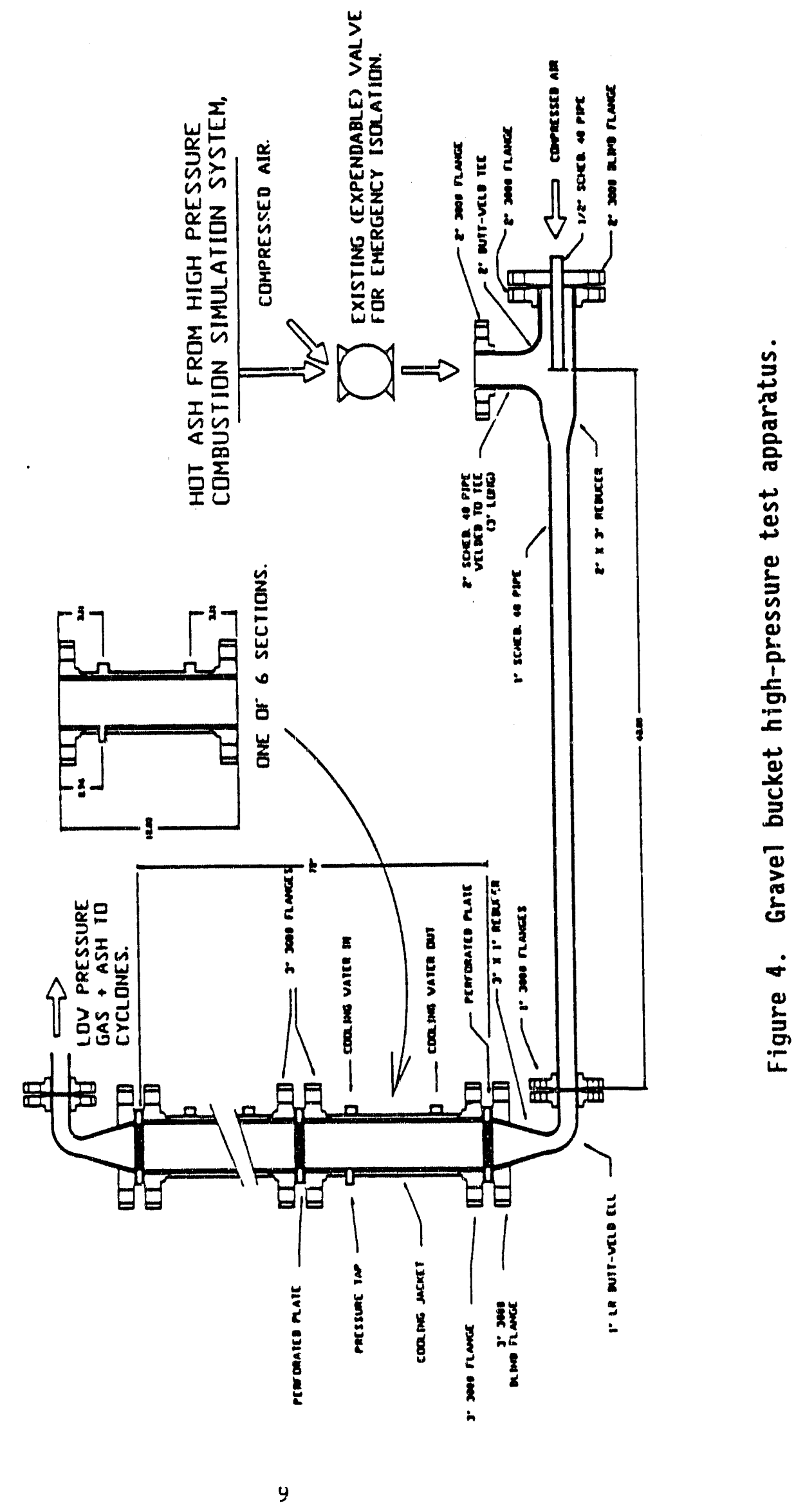


themselves into channels in the lower portion of the chamber, through which the air could flow freely. On. channels became established, no movemunt was observed in the bed. Channels could be eliminated by changing the air filow rate. Slugging was common with the larger bed material. The second phenomenon occurred when sand was introduced into a bed that was partially packed at the top and fluidized at the bottom. Some of the bed rose tu the reverse-packed bed, but the remainder of the lower bed, which had bern fluidized, became fixed. Very little movement of the bed material was observed during periods of sand flow.

Plots of pressure drop per foot ol bed height against fluid mass velocity are shown in Figures 5, 6, and 7. Fluid mass velocity is the mass flow rate of the gas divided by the cross--sectioral area of th? bed. It was originally expected that the mass flow rate term would be based on the effective density of the air-sand mixture; however, Figure 8 shows that the data points with sand plotted in this way are not consistent with the points with air alone. Instead, fluid mass velocity is calculated for the air alcne, and the mass of the solids is accounted for by multiplying the fluid mass velocity by a factor of $(1+X)$, where $X$ is the solids loading (by weight) of the sand. Figures 4 , 5 , and 6 show that the sand data points plotted with this factor are very consistent with the air-only points. Each plot also shows a line which represents the best fit equation for the data shown. These best fit lines were used to develop a mathematical model to predict pressure drop in a gravel bucket (see below). These results and the following mathematical model are covered in more detail in previous publications $(6,10)$.

\subsection{Mathematical Model}

Since a strong correlation between pressure drop per foot of bed height and fluid mass velocity is evident from the plots, an empirical equation was calculated to best fit each set of data. The equations proved to be quite simple in comparison to theoretical pressure drop equations. The predictive model took the following form:

$$
d P / L=C G^{b}
$$

where the constant $C$ and, to a small degree, the exponent $b$, vary with each bed material. Next, these empirical constants and exponents were plotted against their respective packing particle diameters, shown in Figure 9 . It was expected that these would be smooth functions for the three sizes of ceramic spheres, with the limestone and lava rock falling somewhere outside the lines, but the equations shown in Figure 9 appear to apply to all of the particles studied, independent of particle properties such as density and shape. The only exception is the exponent for limestone, which is somewhat lower than that predicted by the equation. This is likely due to the fact. that many of the limestone particles were at least two inches long, while the diameter of the test section was only four inches. This high ratio of particle-to-column diameter causes wall effects and detracts from uniform bed behavior. 


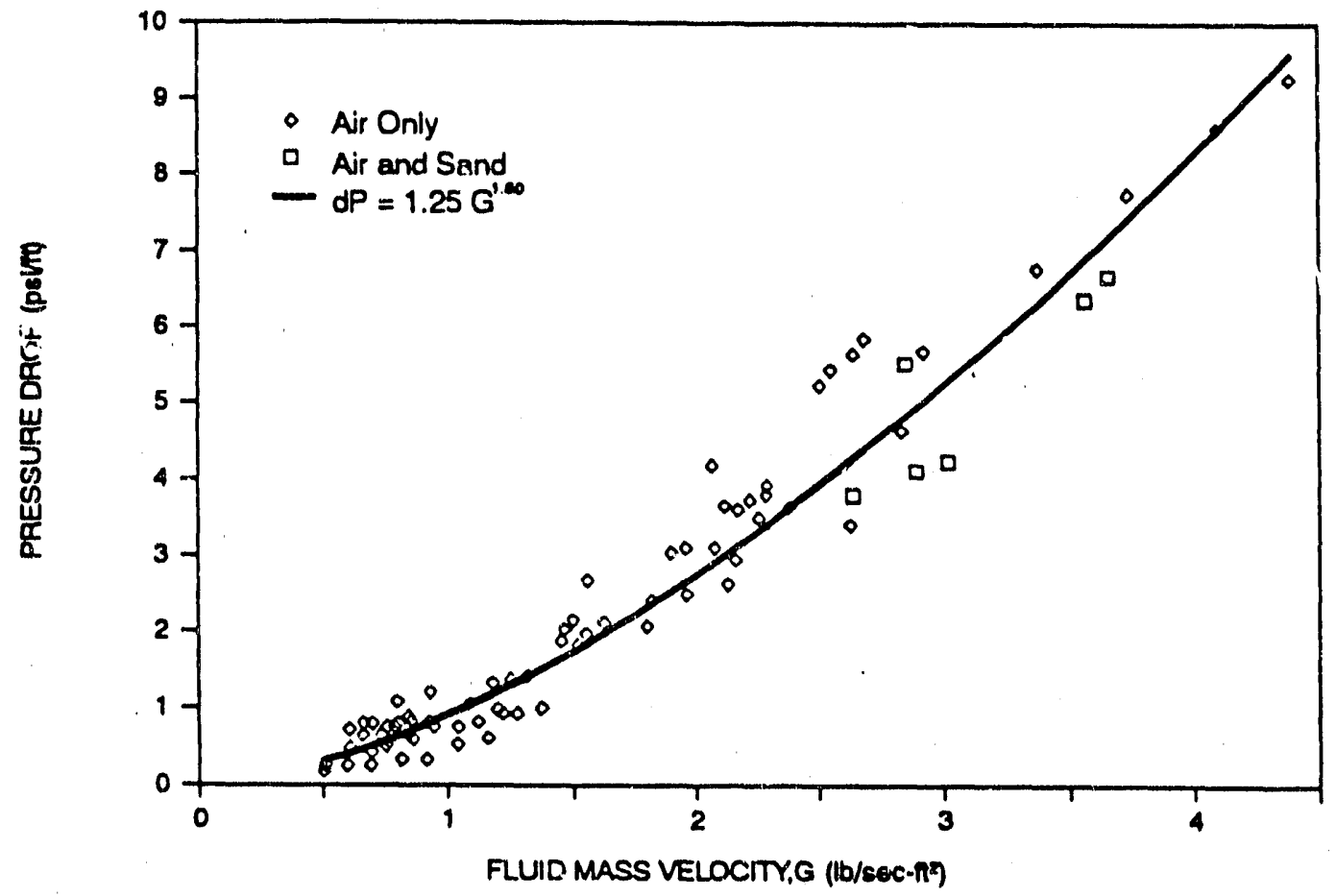

Figure 5. Pressure drop data for $3 / 8^{n}$ lava rock.

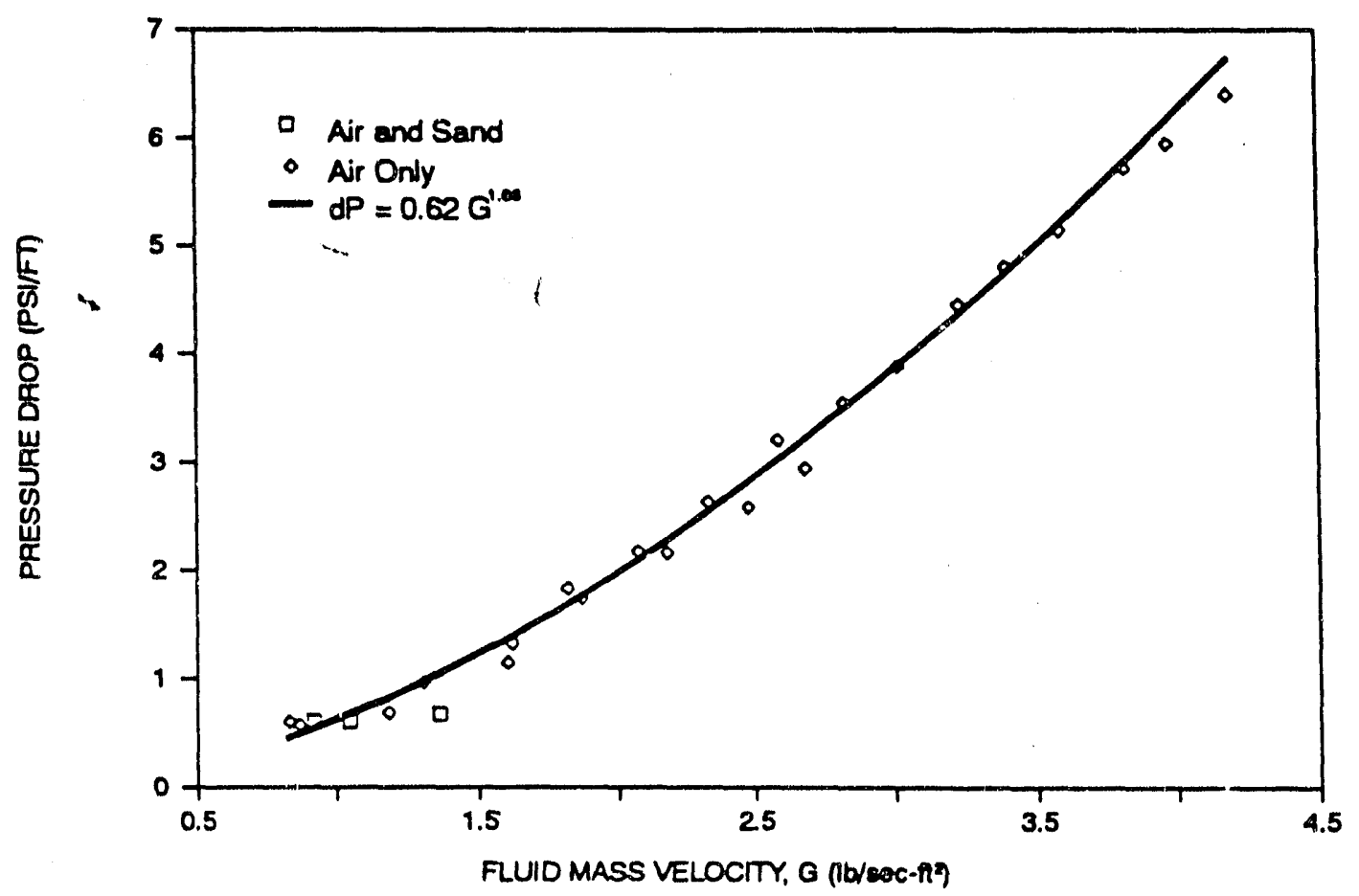

Figure 6. Pressure drop data for $1 / 2^{n}$ ceramic spheres. 


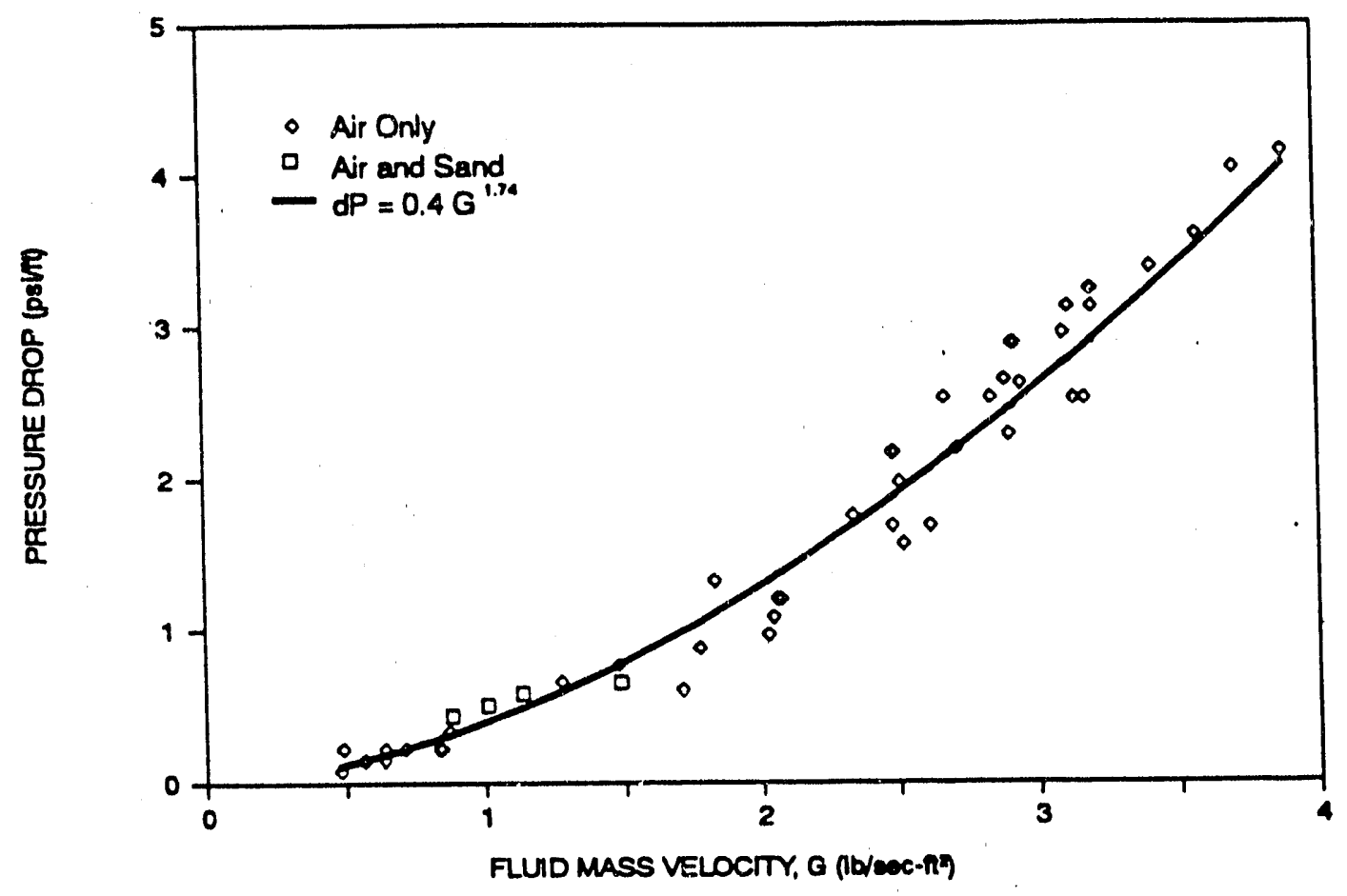

Figure 7. Pressure drop data for $3 / 4^{\text {" ceramic spheres. }}$

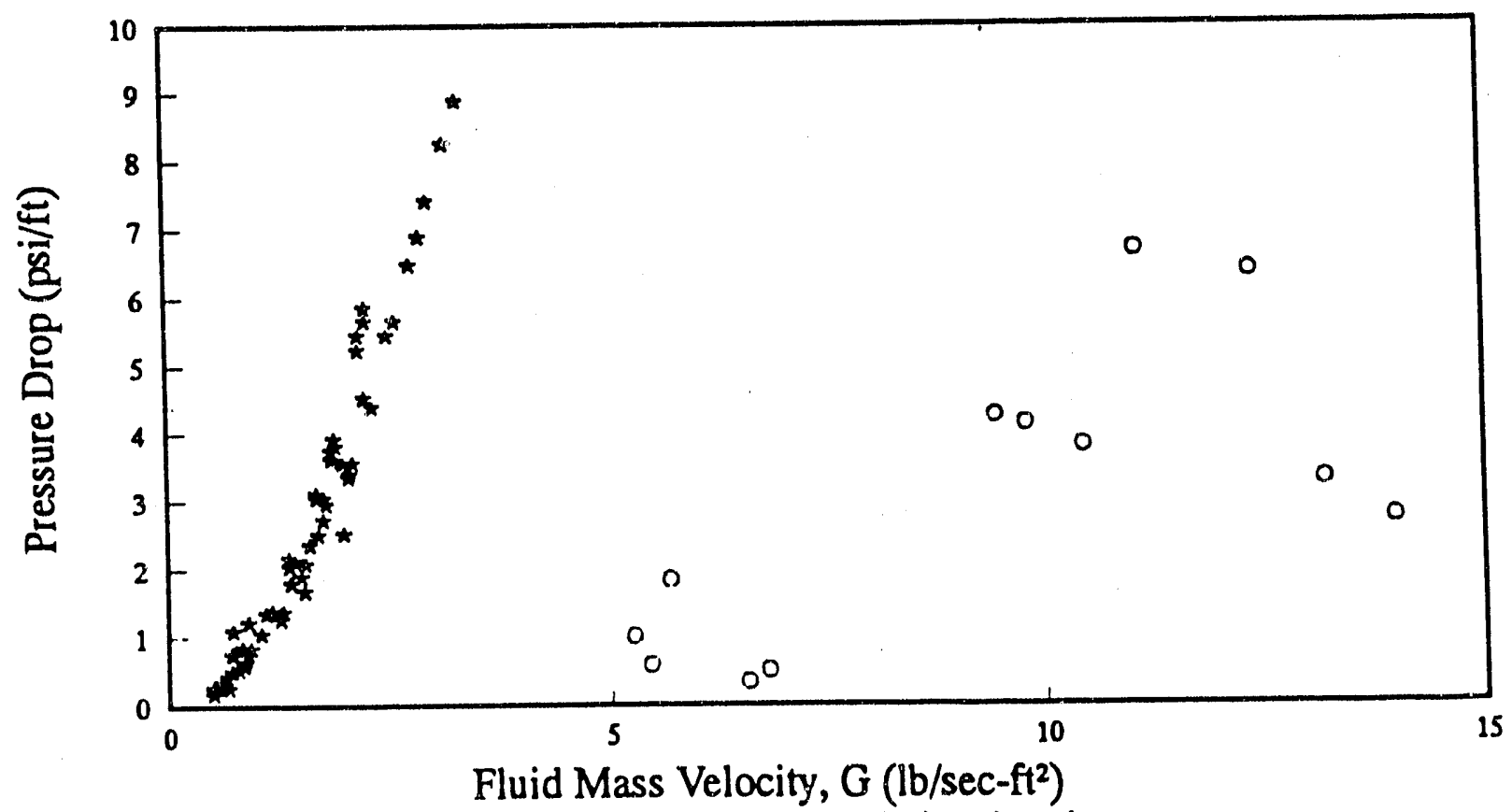

Fluid mass velocity is based on the mass flow rates of both air and sand.

Figure 8. Pressure drop data for lava rock, where fluid mass velocity is based on the effective density of air and sand. 


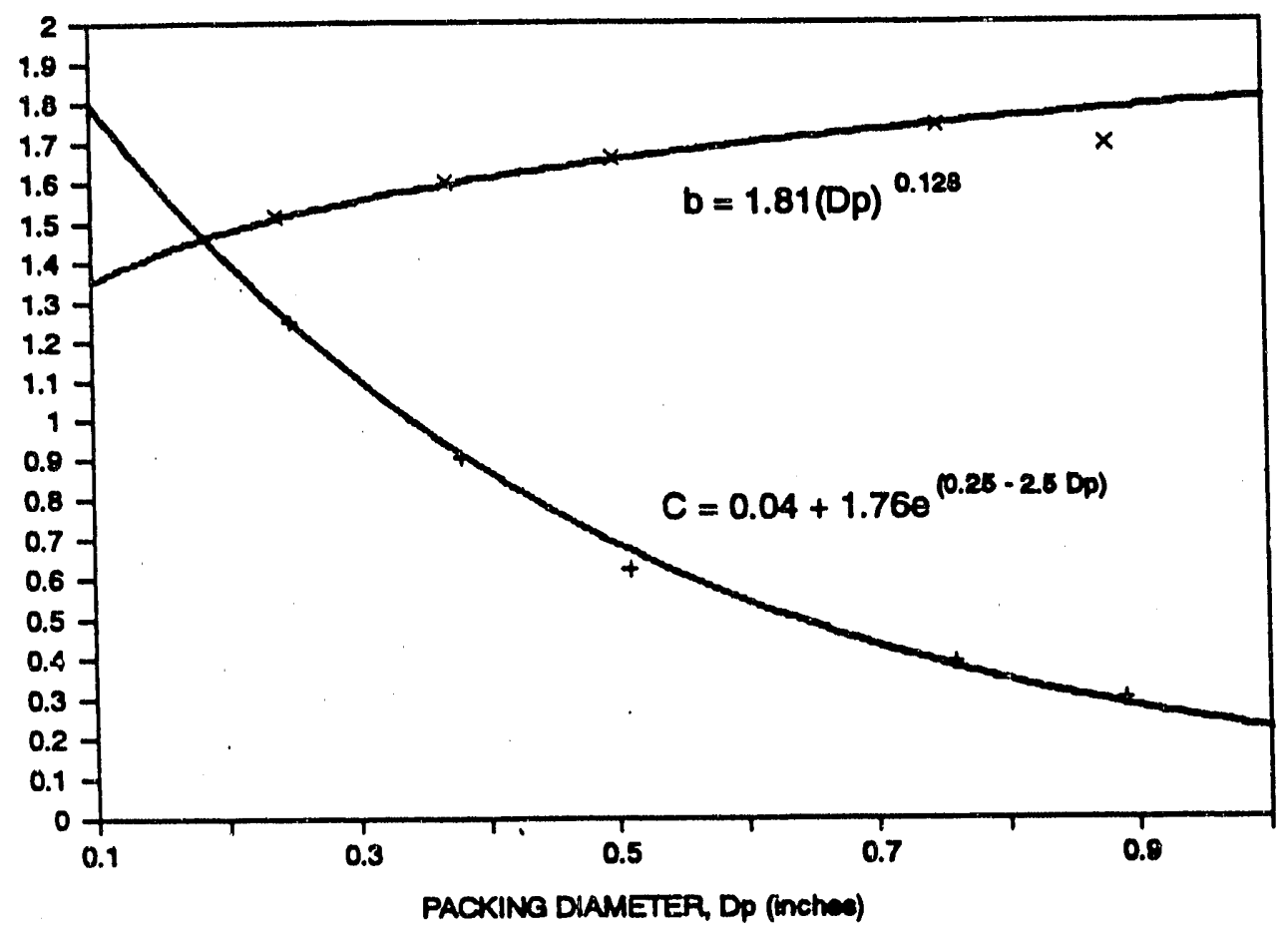

Figure 9. Dependence of constant $C$ and exponent $b$ on packing particle diameter.

\subsection{High-Pressure Results}

Three runs were performed with the high-pressure gravel bucket apparatus. Run 1 was done on the first bed configuration, with the bed separated into five $20 "$ sections, at ambient temperature. The pressures recorded at each level are shown in Figure 10. The figure shows only one hour of data; several hours of repetitious data were omitted from the graph. While the greatest pressure drop occurs at the top of the column, two different regimes could be achieved. If the rate of air flow to the gravel bucket was increased gradually, a more even pressure distribution was obtained, shown in Figure 10 as the area between 0.35 and 0.75 . To obtain the distributions shown between 0.2 and 0.35 , and between 0.82 and 0.95 , where virtually all the pressure drop is across the top section of bed, the flow was quickly increased from zero. This would probably be the case in a PFBC situation.

The pressure data from Run 2 is shown in Figure 11. Once again, repetitious data was omitted from the graph for simplicity. In this run, the intermediate distributor plates were removed, so that the bed consisted of a single bed 100 inches high. This left an empty space of 30 inches between the top of the bed and the upper distributor plate. This configuration allowed pressure readings to be taken within a single bed, rather than just across a bed, as had been done previousiy. The most prominent features of Figure 11 are the spikes at 0.1 hour, and between 0.95 and 1.5 hours. For the majority of the run, at least a portion of the rock was held against the upper 


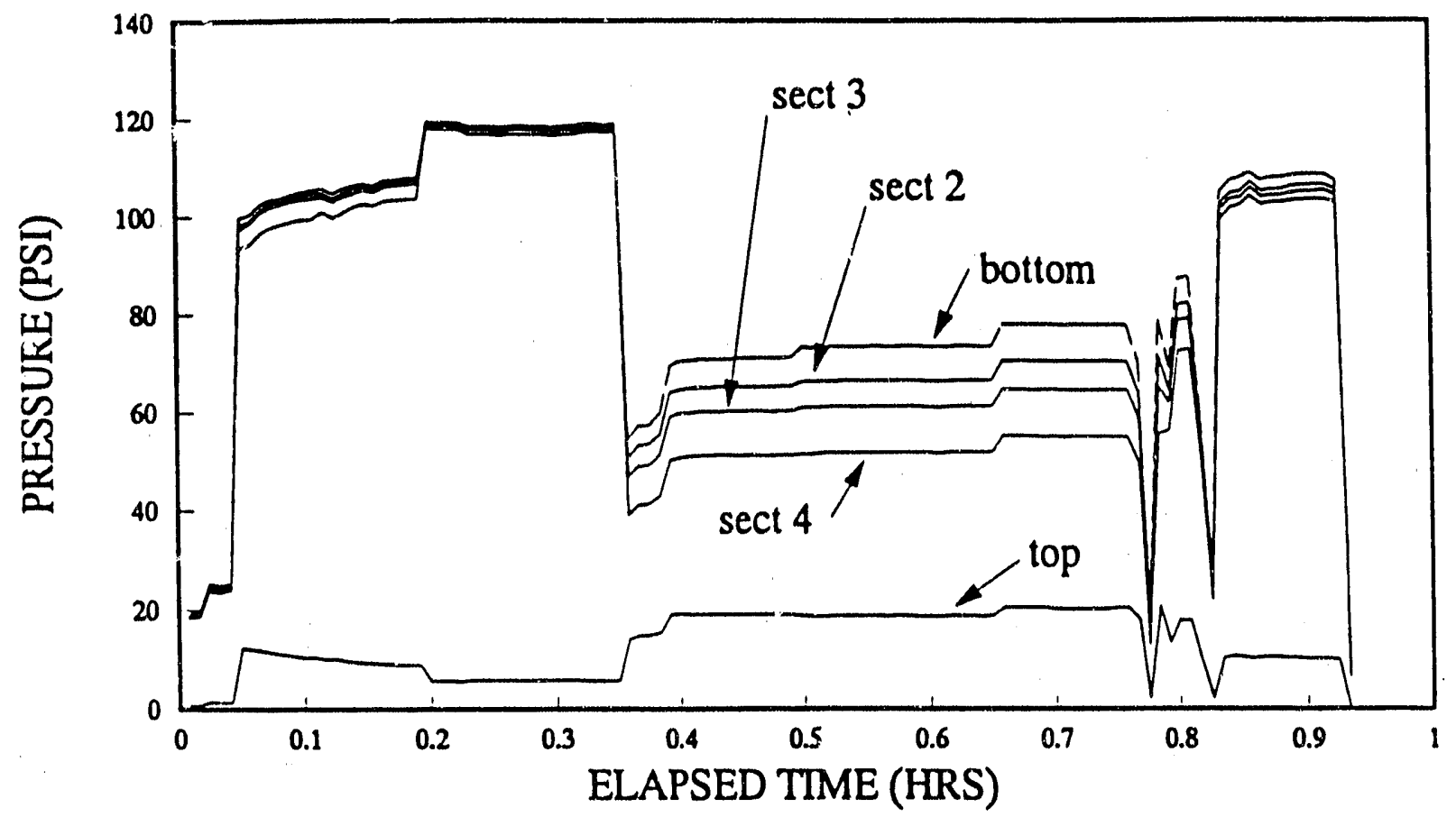

Figure 10. Pressure distribution for high-pressure test \#1.

retaining piate, as the pressure drop between the last two pressure transducers indicates, and a portion stayed at the bottom of the column, indicated by the drop in pressure between the two bottom transducers. However, the bed apparently dropped down periodically, leaving a void or a very smali level of rock above the Section 5 transducer (in a no flow state, the level of the bed was below this transducer). Not only did this collapsing create spikes in the exit pressure, but the prassure at the level of the Section 2 transducer increased, due to the sudden compressing of the air in the space between the upper and lower beds. This fast transient phenomenon demonstrates the metastable nature of a reverse-packed bed and the ease with which it can briefly fluidize, as in the far right illustration of Figure 1. The exact conditions triggering these events, however, were not determined.

The next noteworthy feature in Figure 11 is the increase in both pressure and pressure drop at about 2.7 hours. This coincided with ash injection to the turbine. The capacity of the ash feeder was lower than expected, and only about 3.5 pounds of ash was fed in an hour's time, but ine effect on the gravel bucket performance is apparent. It was predicted that most of the ash would pass through the gravel bed and be collected in a cyclone downstream, but in fact most of the ash collected on the sides of the column or in void spaces within the bed. This effectively decreased the average particle diameter of the bed material, which explains the increase in pressure drop.

As predicted by both theory and intuition, the addition of ash to the air stream resulted in an increased pressure drop. The amount of ash that could be fed by this method, however, was nearly two orders of magnitude smaller 
than the solids loading of $80 \%$ observed in the cold simulation tests $(6,10)$ and predicted by theory. Intuition also suggests that a minimal amount of ash should be statically entrained in many smali, stagnant interstices of a packed bed, which was never exceeded by the small ash flow achieved here.

The ash feed system consisted of a small pressurized reservoir and a rotating pocket valve, from which the ash was carried to the combustion zone through $3 / 8^{n}$ tubing. This system was developed for sorbent injection and used for $\mathrm{SO}_{2}$-capture studies. The alternative ash feed systems considered would have required elaborate construction and developmental efforts beyond the capacity of this project.

Run 3 was a half-day run, during which modifications were made to the ash feeder to try to increase ash flow rate. While a greater flow rate was not achieved, data was collected for a few more hours. Because it is essentially the same as the secorid half of the Run 2 data shown in Figure 11, it is not presented here. At the beginning of the run, approximately a half pound of ash was collected in the cyclone. This was apparently released when the bed was slumped and refluidized between runs.

\subsection{Control System Concepts}

The successful function of a gravel bucket device depends on the design assumption that an imposed pressure drop, equal to the PFBC system pressure, will result in a flow of ash and carrier gas somewhere within the desired range, to remove ash from the system as fast as it is generated, with minimum loss of heat or input air compression energy. This design range can be established by proper selection of three factors: the vessel geometry and the height and particle size of the packing material.

The latter two factors, however, are subject to substantial variation as a result of attrition between recharging, and the ash-to-gas ratio is likely to vary uncontrollably within some undetermined range. Even though the gravel bucket is largely self-controlling, with the theoretical reverse fluidizing feature to avoid plugging, some positive, manual backup control features are still essential.

The following are such automatic control concepts as would be needed to preclude various worst-case operating scenarios. Figure 12 presents four different control loops, to ensure that the basic design assumptions are maintained. None of the suggested instrumentation will be exposed to excessively hot or erosive conditions and will present no exceptional maintenance problems. The particular gravel bucket design variant shown is a single chamber, for simplicity. It introduces the idea of a tapered vessel, which will reduce the chances of wall friction adding support to an upwardiy impacted bed that should be collapsing, which has been observed in tail, slender gasifier vessels $(4,5)$.

The EMERGENCY BLOWBY SHUTDOWN CONTROL, based on laboratory results reported here, is unlikely to ever be needed. If, however, some stable channel should form through the packed bed, venting the full system pressure to the atmosphere, the system must immediately shut down to avoid massive loss 


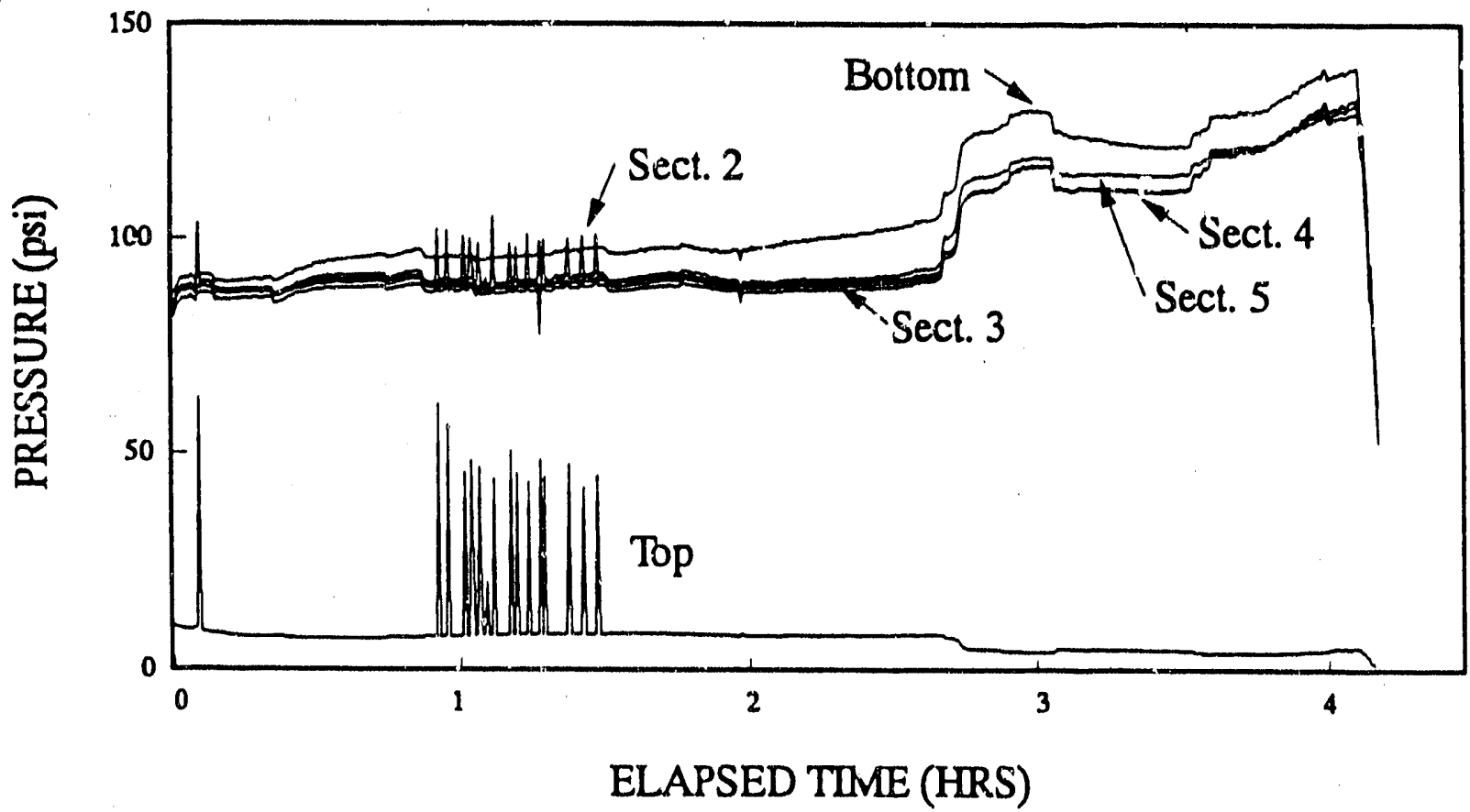

Figure 11. Pressure distribution for high-pressure test \#2.

of hot gases and damage to the downstream piping and stack. The pressure in the top of the column will normally be essentially the design pressure of the downstream piping, assumed here to be 20 psig maximum. For safety reasons, the vessel and all piping, up to and including the emergency block, must be rated for full PFBC system pressure. (In this case, the typical PFBC operating pressure of 150 psig is cited, although actual design codes and practice will require substantial safety factors.) If the pressure in the top of the vessel exceeds the 20 psig set point, an alarm will sound and the emergency block valve will close, shutting down the gravel bucket system. With the flow thus stopped, the reverse-packed bed would presumably collapse, eliminating the channel and allowing normal operation to resume.

The PRIMARY CONTROL LOOP assures the most essential design condition. It maintains the minimum flow required so that the largest ash particles or attrition products will keep moving upward through the system. Attrition products refer to the bed materia?, worn down by use until they are small enough to pass through the holes in the retaining plates. This controlled flow, measured for convenience in the low-pressure discharge line and temperature compensated, will be selected well above the entrainment velocity, at the maximurn bed diameter, for particles of the selected size. Since thenormal gas flow through the system will greatly exceed this requirement, the primary control loop will normally be turned off. It will be extremely valuable in case of temporary loss of pressure in the PFBC system, to prevent possible plugging. 


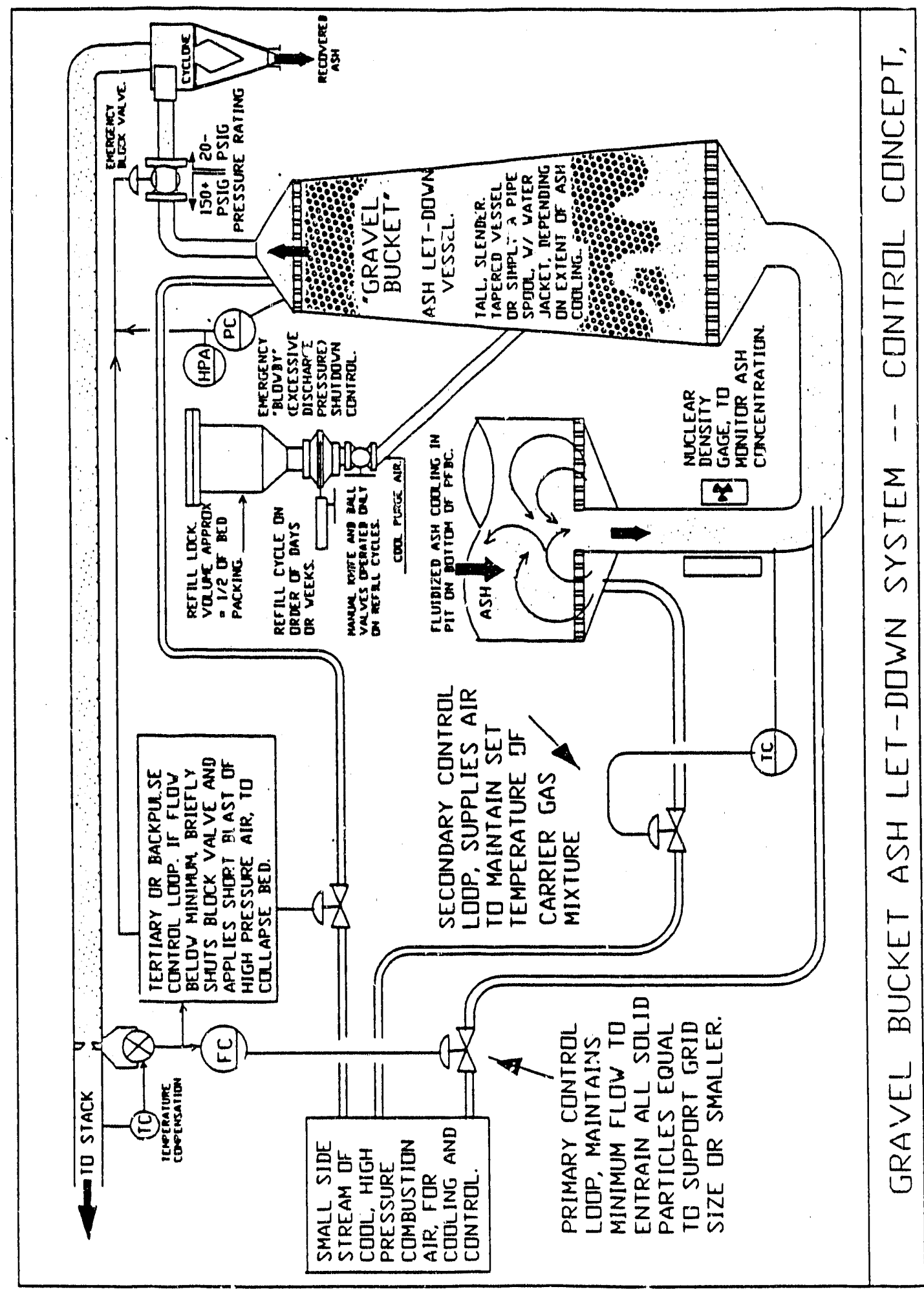


The SECONDARY CONTROL LOOP is simply a temperature controller, supplying air to the PFBC's ash cooler. In its absence, only hot combustion gases would carry hot ash through the grave? bucket, representing a significant waste of heat. Hot ash from the PFBC combustion zone is assumed to drain through a hole in the main distributor plate and into the much smaller pit shown. Here it is cooled and kept fluidized by the cool air supplied by the secondary control loop, most of which will rise into the combustion zone, thus scavenging the heat from the cooling ash and contributing to the combustion air. The bed ash in the cooling pit is assumed to be denser than the fuel bed in the combustic: zone, but must be fluidized to minimum turbulence to maintain flow down the drain to the gravel. bucket. The use of cool air and ash enhances gravel bucket performance, requiring less air because of its greater density and putting less thermal stress on the materials of construction. The actual carrier gas passing to the gravel bucket will be some mixture of cool air and hot combustion gases, depending on the secondary control loop setting, degree of turbuience in the hot ash pit, and pressure excursions in the PFBC system.

The TERTIARY or BACKPULSE CONTROL LOOP will be invoked if an upwardly impacted bed becomes too dense to pass some minimum, preset flow and does not coliapse or reverse-fluidize, as predicted by theory. In this event, the tertiary loop will detect the no-flow condition, or at least some minimum set point, below that of the primary control loop. It would then first close the emergency block valve and then pressurize the gravel bucket from the top with full pressure combustion air, at a pressure slightly higher than the PFBC system pressure. This would reverse the pressure drop through the gravel bucket, thus assisting gravity to collapse the bed. After a preset second or two, it would turn off the air and reopen the block valve.

Note that all four of the above control functions are essentially fallback provisions, to operate only if the gravel bucket fails to function as predicted. While these control loops and the gravel bucket design will determine the gas flow through the system, they appear to have litt.le bearing on the amount of ash entrained in the gas, which should be as near as possibie to the theoretical limit of around $80 \%$ solids, to avoid an excessively large gravel bucket and the compression cost of excessive air. The ash-to-gas ratio entering the gravel bucket system will probably be determined largely by the ash pit design and is thus effectively beyond the scope of this study. However, upon considering the ash pit design shown schematically in Figure 8 , it is apparent that the amount of ash going down the drain will be dominated by the air stream from the secondary control loop. Clearly, if the upward air flow is excessive, it could simply prevent the ash from settling into the pit, and if it were too low to fluidize completely, the ash would simply settle and lack mobility toward the drain. It is, therefore, recommended that the first operational gravel bucket on a full-scale PFBC plant be equipped with a nuclear density gauge on the ash pit drain, to determine the effect of cooling air flow on flowing ash density, so that the ash cooling pit design could be optimized. 


\subsection{CONCLUSIONS}

- The gravel bucket device has been shown to be effective as a pressure letdown device on a stream of high-pressure ash. To achieve pressure drops graater than the weight of the bed material, the bed remains packed against the perforated plate forming the roof of the gravel bucket chamber.

- A mathematical model was developed based on empirical data generated in the cold flow simulator. However, the model was based on the assumption that the pressure drop across a reverse-packed bed would be evenly distributed across the entire height of the bed. High-pressure testing revealed that the majority of the pressure drop in a gravel bucket is concentrated in the top part of the bed. The actual height required to provide the required pressure drop is not calculable with the present data set, though it is obviously much less than originally expected.

- In practice, attrition will reduce the size of the packing particles, causing the bed height to decrease. Intuitively, this suggests a decrease in total pressure drop across the bed, requiring frequent rock addition to maintain the desired pressure drop. However, pressure drop per foot of bed height increases as packing size decreases (Figure 13), so that as the bed material gradually erodes, it becomes more efficient. This phenomenon will allow for much longer intervals between rock addition than first assumed. The exact interval will depend on the initial particle size and the erosion resistance of the rock.

- Reverse fluidization as a method of unplugging a bed impacted with solids was not observed; plugging simply never occurred in the test units. The researchers believe that reverse fluidization will be an effective means of releasing trapped ash; however, additional control mechanisms may be necessary.

- The key to practical evaluation of the gravel bucket design concept is that the operating cost per capacity be significantly less than the cost of an equivalent lockhopper system, taking into account a realistic assessment of valve trim replacement costs. Such an economic analysis is being prepared as a separate report (11).

- The high-pressure test unit is available for subsequent testing and development on an operating PFBC plant, should such an opportunity become available.

- Future work, beyond the scope of this project, should attempt to verify the reverse fluidization phenomerion by intentionally plugging a gravel bucket and to explore the effects of a wider range of bed design. More data needs to be collected to present a clear picture of the pressure distribution in a reverse-packed bed and to develop a valid mathematical model. Another area for further research is in the area of bed material erosion. 


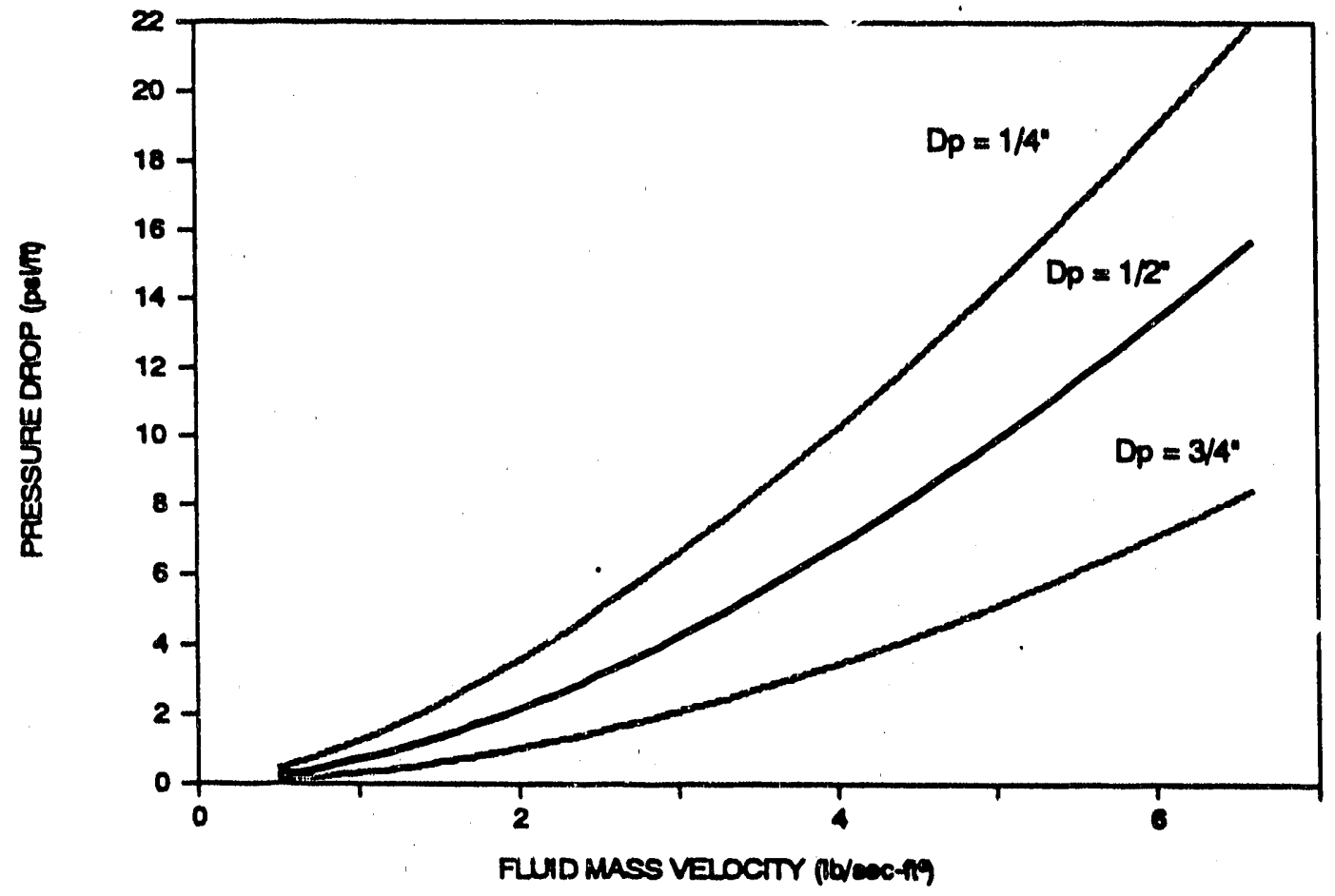

Figure 13. Effect of packing particle diameter dP on pressure drop.

\subsection{REFERENCES}

1. Hauserman, W.B.; Johnson, M.D., "Use of Cheap, Sacrificial Materials for Valve Trim in Erosive Slurry Applications," Final Report, Project DE-AC21-85MC22109, Apri1 1987.

2. Johnson, M.D.; Hauserman, W.B. "Use of Cheap, Sacrificial Materials for Valve Trim in Erosive Slurry Applications - 2: The Gravel Bucket Valve," Second Interim Report, Project DE- C21-85MC22109, April 1987.

3. Leva, Max. Fluidization; McGraw-Hill: New York, 1959.

4. Hauserman, W.B.; Willson W.G. "Mechanical Problems in the Design of a Fixed-Bed, Slagging Gasifier, "ASME Energy-Sources Technology Conference and Exhibition, Houston, TX, Jan. 30 - Feb. 2, 1983.

5. Hauserman, W.B. "Structural Properties Affecting the Settling of Coarse Crushed Coal in Gasifiers," ASME Energy-Sources Technology Conference and Exhibition, New Orleans, LA, Feb. 12-16, 1984.

6. Hauserman, W.B.; Henderson A.K. "Valveless Ash Removal From Pressurized Fluidized Bed Combustion Systems," ASME Energy-Sources Technology Conference and Exhibition, New Orleans, LA, Jan. 14-18, 1990. 
7. Knowlton, T.; et al. (Institute of Gas Technolngy). "Solids Pressure Reduction Without Lockhoppers: The Restricted Pipe Discharge System," AIChe Symposium Series, 1988.

8. Demeter, J.J.; Haynes W.P. "Downward Flowing Granular Solids as Pressure Seals in Vertical Standpipes," U.S. Department of the Interior, Bureau of Mines, RI-5745, 1961 .

9. Carlson, P.K. "Packed Bed Pressure Letdown Studies," Oak Ridge National Laboratory. Interim Report ORNL/CF-80/338, September 1980.

10. Henderson, A.K.; Hauserman, W.B., "Valveless Ash Removal From Pressurized Fluidized-Bed Combustion Systems," Seventh Annual Coa1Fueled Heat Engines and Gas Stream Cleanup Systems Contractors' Review Meeting, Morgantown, WV, March 26-28, 1990.

11. Hauserman, W.B.; Henderson A.K.; Haley J.S., "Economic Comparison of a Gravel Bucket-Type Ash Letdown Device with Conventional Lockhoppers for Pressurized Fluidized-Bed Combustion Systems," EERC, under U.S. DOE Contract DE-AC21-89MC252151, November 1990. 


\title{
APPENDIX A: \\ ECONOMIC COMPARISON OF A \\ GRAVEL BUCKET-TYPE ASH LETDOWN DEVICE \\ WITH CONVENTIONAL LOCKHOPPERS FOR PRESSURIZED \\ FLUID-BED COMBUSTION SYSTEMS
}

\author{
William B. Hauserman, Project Manager \\ Ann K. Henderson, Research Engineer \\ Energy and Environmental Research Center \\ University of North Dakota \\ Box 8213, University Station \\ Grand Forks, ND 58202
}




\section{TABLE OF CONTENTS}

Page

1.0 INTRODUCTION AND OBJECTIVE . . . . . . . . . . $\ldots$

2.0 BACKGROUND AND BASIS OF COMPARISON ............

2.1 Most Similar Ash Letdown Systems .......................

3.0 GRAVEL BUCKET DESIGN ASSUMPTIONS . . . . . . . . . . . 14

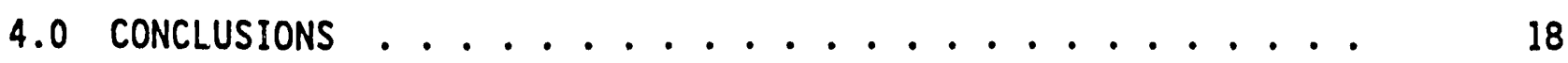

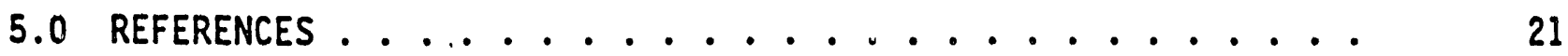




\section{LIST OF FIGURES}

Eiqure

Page

1 Gasifier ash lockhoppers at the ANG/Beulah Plant ......

2 The GFETC slagging fixed-bed gasifier ............

3 Lockhopper optimization . . . . . . . . . . . . .

4 Worst-case lockhopper design ................

5 Most probable gravel bucket system design, fully instrumented

6 Worst-case, multiple-chamber gravel bucket ..........

7 Gravel bucket optimization ................

\section{LIST OF TABLES}

Table

Page

1 Operating Economics of Gasifier Ash Lockhoppers at the Great Plains Gasification Plant, Beulah, ND.........

2 Costs of Available State-of-the-Art Valves Suitable for Hot, Abrasive Ash Handling ....................

3 Operating Economics of a Conventional Lockhopper System ...

4 Sensitivity of Economic Model to Parameters Other Than

Base Case........................

5 Economics of a Gravel Bucket Ash Letdown System ........ 


\section{ECONOMIC COMPARISON OF A GRAVEL \\ BUCKET-TYPE ASH LETDOWN DEVICE WITH \\ CONVENTIONAL LOCKHOPPERS FOR PRESSURIZED \\ FLUID-BED COMBUSTION SYSTEMS}

\subsection{INTRODUCTION AND OBJECTIVE}

This is an economic comparison of a hypothetical gravel bucket pressure letdown device with a conventional lockhopper to remove coal ash and spent-bed material from a pressurized fluid-bed combustion (PFBC) system. A gravel bucket is a vessel filled with coarsely crushed rock which is frequently and cheaply replaced. The alternative is a conventional lockhopper, in which costly valves of some sort are damaged by erosive wear, needing frequent replacement. This study is belatediy submitted as Task 1.2 under U.S. DOE Contract No. DE-AC21-89MC25151. The fundamental concept of the gravel bucket ash letdown device and results of cold simulation and preliminary pilot-scale testing have been described in a final report of that contract (1).

The objective of the work reported here is to estimate capital and maintenance costs of a gravel bucket ash letdown device for comparison with estimates of conventional alternatives. Costs will be expressed in dollars per ton of ash removed. This effort is severely limited by uncertainty as to practical gravel bucket design and by limited availability of accurate cost factors for comparable systems, especially regarding useful life and replacement frequency of valves in not-yet-existent prototype PFBC systems.

The intent here is to render an objective comparison of conventional lockhopper and gravel bucket costs for PFBC ash removal. Recognizing that EERC has an intrinsic bias in favor of the gravel bucket, all of tine following assumptions are stretched as far as credible in favor of minimizing lockhopper costs. Although limited by availability of input cost data and severely limited by useful life data on valves under the service conditions of interest, sensitivity analyses are done to identify possible best-case conditions for lockhopper design and cost projections.

\subsection{BACKGROUND AND BASIS OF COMPARISON}

Briefly, a gravel bucket is a device in which a high-pressure stream of abrasive solids, carried either in liquid as a slurry or in suspension in a gas, is passed through a bed of coarsely crushed rock to provide a controlled pressure drop equal to the operating pressure of the system from which the . solids must be removed. All abrasive wear is thus inflicted on the cheaply replaceable crushed rock, rather than on expensive valve trim $(1,2)$. The original gravel bucket concept (3) was intended as an alternative to siurry throttling valves for high-pressure coal liquification processes. The present project was conceived to extend slurry data to streams of gas-borne ash leaving fluid-bed combustion processes.

Lockhopper designs are fairly interchangeable. Operating data specific to iockhoppers for hot ash from pressurized fluidized-bed combustion (PFBC) systems is generally nonexistent, however, because no such systems have been 
operated long enough, following the selection and installation of the best available valves to yield realistic maintenance data. Valve performance data from PFBC developmental programs is only qualitative. Typically (4), Valve A failed almost immediately and was modified in-house or replaced by customized Valve B, which performed without problems for the remainder of the project, about 300 hours of operation. For any comparison of ash letdown systems to be meaningful, it must be based on routine, long-term replacement costs for a hypothetical, fully commercial PFBC utility plant. Costs of the best valves available are obtainable. Useful life--expressed in terms of cperating cycles and cumulative tons of ash passed--is, at this point, purely specu?ative.

\subsection{Most Similar Ash Letdown Systems}

As a design basis for a PFBC application, the problem with "most similar" systems is that they simply do not exist. The only example that could be found was the 14 ash letdown lockhoppers at the Great Plains coal gasification plant at Beulah, North Dakota, operated by Dakota Gasification Company (DGC). Some maintenance costs for the Great Plains coal gasification plant are reported (5) and used here as a possible "worst case." The design of these lockhoppers is shown in Figure 1. They are purged with superheated steam during the dumping cycle. The gasifier ash is highly cementitious and tends to be more abrasive than combustion ashes in general (6). Furthermore, the ash is less free flowing than PFBC ash, containing fused clinkers often up to a foot in diameter. For this reason, the flapper valves are designed with roughly 12" openings. Furthermore, the fairly complex linkages operating . these valves are immersad in the abrasive ash, requiring roughly annual major repairs. The dominant failure mode, however, is fajlure to seal, due to both abrasive and impact damage of the mating surfaces.

Data on DGC's lockhopper replacement cycle is summarized in Table 1. Their annual rebuilding of lockhoppers accounts for a major portion of the plant's maintenance efforts, and their repair shop is esse'itially a lockhopper production facility. While the qualitative description of the DGC operation sounds like a worst case, it should be kept in mind that no repeating or replacement market yet exists for state-of-the-art valves to operate under DGC's conditions or those of commercial or even demonstration PFBC systems. Therefore, DGC is prcibably the leading mass producer of valves within the range of conditions discussed here and may thus have achieved some significant economy of scale. The rebuilding of flapper valves at DGC is extremely labor intensive, as shown in Table 1. The assumed labor rate, based on discussion with DGC management, is roughly that at which DGC would break even if they were in business to produce such valves for sale.

The estimated cost of $\$ 1.54$ to $\$ 2.05$ per ton, just to get the ash out of a pressure vessel, establishes a target for improvements. The actual operating cost to DGC may be even higher, if the cost of shutting down and restarting a gasifier, internal rescheduling of process flows, and temporary loss of throughput capacity were charged to the "failure cost" of the valves On the other hand, if DGC were in the business selling such valves for a profit, an added gross margin of 30\%, for example, would raise these costs to $\$ 2.00$ tc $\$ 2.67$ per ton of ash passed. 

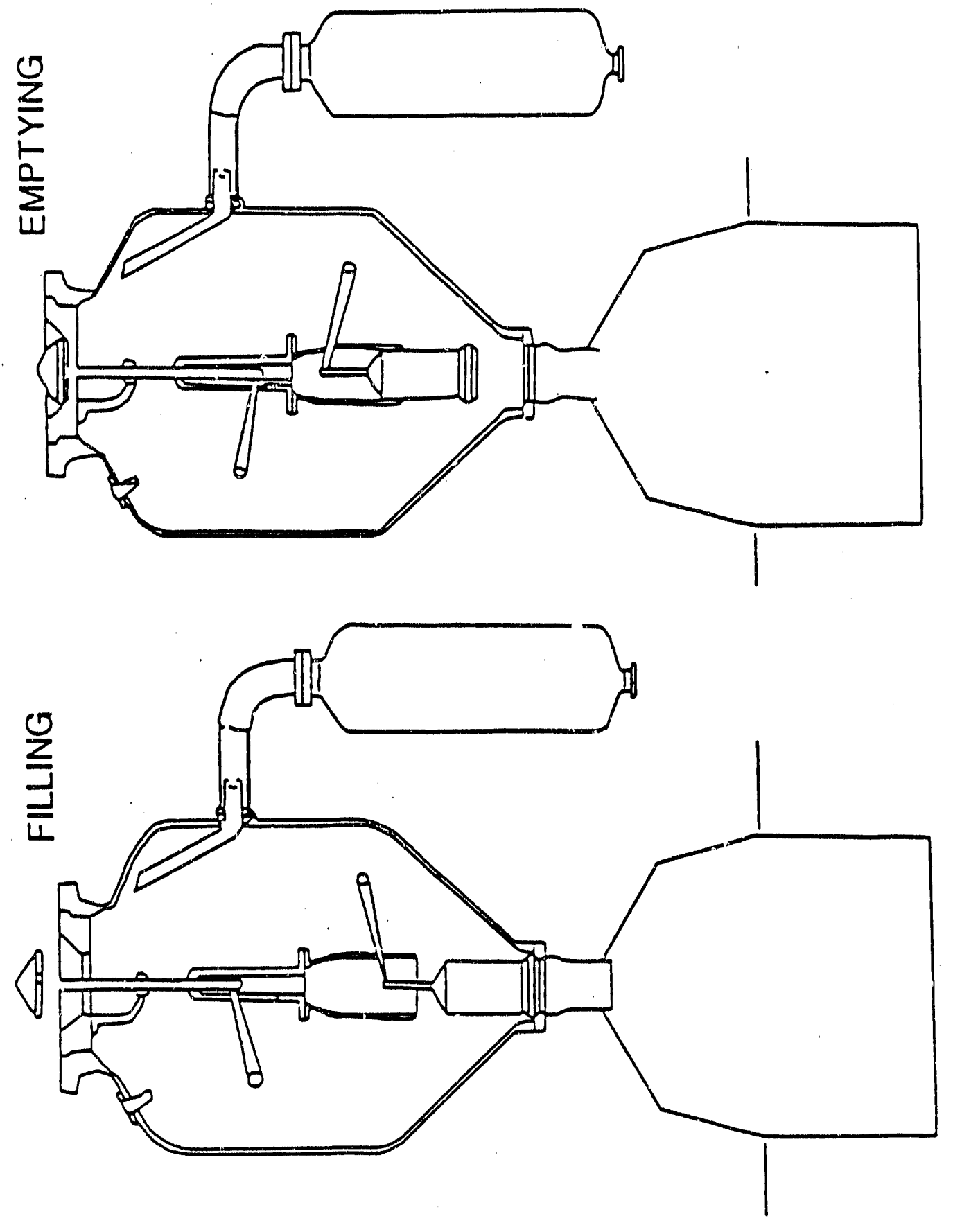

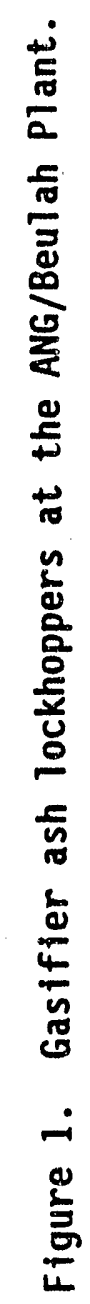


Number of gasifiers

Number of ash lockhoppers ${ }^{1.2}$

Average in-service time between rebuilding

Ash throughput per hopper per cycle

Average cycle time

Cycles between rebuilding

Tons of ash per hopper between building
14

16

6 to 8 mos

3 tons $/ \mathrm{hr}$

$1 \mathrm{hr}$

4,320 to 5,760 cycies

12,900 to 17,280 tons

Estimated maintenance man-hours to remove, rebuild, and instal? lockhoppers

and valves"

Average labor rate

Materials to rebuild one ash lockhopper

Total cost per each rebuilt ash lockhopper'

Annual plant cost for ash lockhopper repair

475 man-hrs

$\$ 51 / \mathrm{hr}$

$\$ 2,600$

$\$ 26,608 /$ hopper

$\$ 745,035$ to $\$ 558,776 / \mathrm{yr}$

Cost per ton of ash throughput

$\$ 2.05$ to $\$ 1.54 /$ ton

${ }^{2}$ Allowing for two hoppers to be in shop for rebuilding at all times.

2This will be increased to 17 after 7 years of operation, as more extensive repairs (1ine boring) will be needed to compensate for longer-term wear, increasing maintenance costs sightiy.

${ }^{3}$ Plant operates 355 days per year, with 5-day general maintenance shutdown. Assumes hoppers in continuous operation, 720 hours per month, between individual shutdowns.

"Probably does not include less direct plant operation costs associated with shutdown/start-up to switch lockhoppers, such as lost production, temperary rescheduling flows, etc.

${ }^{5}$ Labor rate estimated by DGC for possible outside contracts, inciuding identified overhead items such as benefits, engineering, and warehousing, but no profit margin. This labor rate is, therefore, a minimal, breakeven condition oniy.

'Steel plate, bar stock, nuts, bolts, and welding rods. Essentially no purchased parts, since design is unique. This is essentially the cost of two valves, since wear on vessel is insignificant.

'Since lockhopper vessels receive little abrasive wear, the entire cost of each can be considered the cost of replacing two flapper valves, which comes to only $\$ 26,60$ er valve, for comparison with valves offered commercially.

-If DGC were in business making valves and added a $30 \%$ gross margin to the above labor cost, the rost range to a buyer, per ton of capacity, would increase to $\$ 2.00-\$ 2.6 \% /$ ton. 
The next step in this evaluation will be to specify a hypothetical ash lockhopper more suited to a PFBC system using commercially available valves. Maintenance costs at DGC are for valves and actuator linkages only, as the ash hopper vessels themselves experience insignificant wear by the ash. Therefore, in the estimating method developed here, vessels and chutes will be treated as long-term, depreciable capital investment, while frequently replaceable valves will be treated as a maintenance expense. "Frequently" will mean any interval that is a small fraction of the capital depreciation period, reported in hours rather than years.

The coal feed huppers on the same Lurgi gasifiers at DGC are simpler in design and require far less maintenance, simply because raw coal is less abrasive. Their cost per tan of coal is not reported, but is presumabiy less than the cost per ton of throuighput. As another case study and possib?e basis of comparison, simple lockhoppers were used at EERC until 1983, on a piintscale, slagging, fixed-bed gasifier (7). The organization was then affiliated with U.S. DOE as the Grand Forks Energy Technology Center. The coal feed lockhoppers shown in Figure 2 were of state-of-the-art design, as of about 1978. They were filled, dumped, and switched roughly every 40 minutes during operation, with an average gasifier feed rate of 0.85 tons $/ \mathrm{hr}$. The temperatule of these feed hoppers was maintained at near ambient, although higher temperatures were possible due to intermittent leakage from the gasifier, primarily when the valves were badily worn. The relatively expensive bali valve (Kamyr) was the primary assurance against leakage, while the cheaper knife-gate valve (Everlasting) over it served to protect the ball valve from having to open with coal piled into it. The upper knife-gate valve was only operated when the hopper was vented, but was expected to contain up to 400 psig when closed.

Referring again to Figure 2, consider the means of removing ash from that gasifier. Coarse, abrasive, quenched slag was removed with water through another lockhopper, equipped with two high-torque plug valves, built many years earlier. Due to the lubricating effects of water, abrasion here was generally less of a problem than for the feed hopper valves, even though the ash was more abrasive than coal. This suggests that a quench chamber with ash removed as a cooled slurry may merit consideration as a means of PFBC ash removal. This approach is even better suited to PFBC applications than to gasifiers, since the ash and spent-bed material are less abrasive and more reliably of fine, uniform size distribution. The possibility is well beyond the scope of this study, however. The coal hoppers, on the other hand, will be considered as a design basis for a conventional lockhopper system.

The Grand Forks gasifier was operated as a research project, limited to many short runs, requiring less than 600 cycles of the lockhopper during 1982, its last and most successful year of operation. Even in this limited service, replacement of both ball and knife-gate valves, due to unacceptable leakage, was a frequent and major maintenance task. Useful life and replacement costs are not easily recoverable and would be of little value, as both valves were off-the-shelf items, presumably greatly inferior to the state-of-the-art valves currently offered for hot, abrasive service. Neither of these valves achieved a useful life of more than a few hundred cycles. 


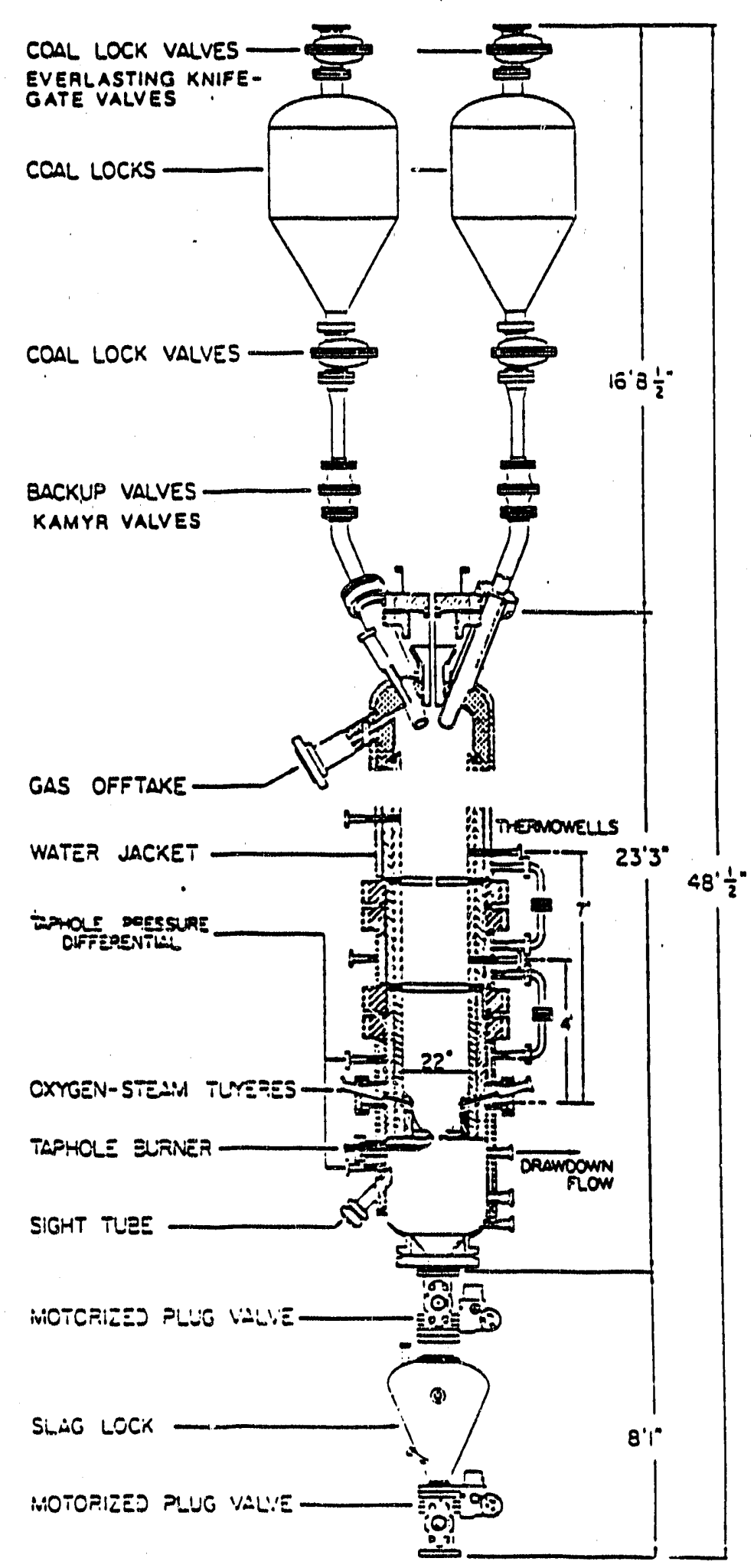

Figure 2. The GFETC slagging fixed-bed gasifier. 
Quotes were received from three valve manufacturers for valves rated for 150 psi at $1500^{\circ} \mathrm{F}$. Table 2 lists these quotations, from manufacturers participating in a relatively recent U.S. DOE study of lockhopper valves for such applications. The salient feature of Table 2 is that costs run roughly an order of magnitude greater than telephone quotes for late 1989 costs of the most nearly similar valves to those used in the system of Figure 2. More disturbing is the fact that quoted valve prices of $6^{\text {" }}$ valves in Table 2 range from two to four times as high as the rebuilding cost of DGC's $12^{\text {" flapper }}$ valves in Table 1. It is unknown how much of the cost of the valves in Table 2 could be salvaged by replacement of trim or by in-house rebuilding. It is assumed here that the major portion of the cost of these valves is in expensive alloys used for the balls (or discs) and seats; replacement of these trim components will amount to roughly replacing the entire valve. As an alternative, an owner would have to negotiate some sort of long-term, replacement parts contract with the vendors, which is well beyond the scope of this study.

TABLE 2

COSTS OF AVAILABLE STATE-OF-THE-ART VALVES

SUITABL.E FOR HOT, ABRASIVE ASH HANDLING

\section{Vendor/Manufacturer and Description}

Cost

1. Everlasting, 6" rotating disc valve, Inconel $800^{\mathrm{HT}}$ disc and seat, $1500^{\circ} \mathrm{F}$ at $150 \mathrm{psig}$, Haynes Alloy 556 post, pneumatic actuator.

$\$ 66,500$

2. Mogas, 6" C-1 ball valve, $1500^{\circ} \mathrm{F}$ at $150 \mathrm{psig,}$ chrome carbide coated seat and ball, electric actuator with controls.

3. Valvtron, $6^{\prime \prime}$ ball valve, $1500^{\circ} \mathrm{F}$ at $150 \mathrm{psig,}$ $316 \mathrm{H}$ body and trim, Metco $19 \mathrm{E}$ coating on ball and seat, electric actuator.

$\$ 27.869$

Range assumed for lockhopper cost estimation:

$\$ 30,000$ to $\$ 67,000$

Comparing the per valve costs of Tables 1 and 2 forces an observation that the presumed "worst-case" of DGC's flapper valves repaired in-house is far cheaper than replacing state-of-the-art valves, even if raplacement parts for the latter were available at half the quoted prices of Table 2 . In the absence of any knowledge of the internal accounting of the valve manufacturers, it may be that the quotes of Table 2 do not represent anything approaching off-the-shelf, mass-produced items. We must observe that there is no current construction boom for PFBC utility plants nor any other process to ensure a market for any massive quantity of valves to provide reliable shutoff 
at $1500^{\circ} \mathrm{F}$ against abrasive solids. It is thus possible that the quoted valves are essentially semicustom items, at prices required to cover major engineering and development costs.

\subsection{Lockhopper System Costs}

As a design basis, consider ash lockhoppers nearly identical to the coal feed hoppers of Figure 2. Let us assume that the cheapest ball valve from Table 2 is installed at the top of the hopper for the critical pressure sealing function, protected from the hot ash by a knife gate over it. The other knife gate would be at the bottom of the hopper. Some amount of gas leakage through the system call be tolerated, as the gas is, unlike the DGC case, inert and noncombustible. It is thus assumed that the more expendable knife-gate valves will survive through 4,000 to 6,000 cycles before they can no longer control the ash flow. The original knife gates used in tl. a Grand Forks project cost roughly $\$ 4,000$ to replace. It is thus arbitrarily assumed, as a first design iteration, that some comparable valve could be bought today for a mere $\$ 10,000$ and will survive through some thousands of cycles of blocking ash flow, if not prevent gas leakage.

It is further assumed that the cheapest $(\$ 30,000)$ valve from Table 2 can survive for one year, or around 13,000 cycles, being subjected only to hot ash dropping through it after it is opened, with abrasive damage caused only by small amounts of residual ash in contact with mating surfaces in motion. This assumption is believed to be very generous in favor of minimizing replacement rates of these costly valves. The METC valve study (8) concludes that currently available valves should offer a tenfold increase in survival over 500 cycles assumed earlier, at temperatures of $1200^{\circ} \mathrm{F}$ and pressures far greater than the 150 psig required for this application. We are assuming here that using a relatively cheap, sacrificial knife gate can double or even triple the nominal 5,000 cycle life of a $\$ 30,000$ valve.

There is, admittediy, no empirical evidence that this assumption is justified. It is used in this first iteration, however, to define a best-case scenario in support of minimal lockhopper costs. Use of a cool blast of purge gas against the upper surfaces of the knife gate and the ball valve just before and during opening may greatly reduce abrasive damage, although this, too, is unsupported by any experimental evidence. Having cut as many corners as possible to minimize valve costs, Table 3 presents one hypothetical set of design conditions, using the vessel size, throughput, and cycle time of the Grand Forks gasifier and the range of useful life, measured in valve cycles observed at the Great Plains plant, to apply to the relatively cheap knifegate valves. If these assumptions are valid, the ash removal cost will range from $\$ 16.81$ to $\$ 28.01$ per ton!

Since valve replacement is the major contribution to annualized operating costs, one way to reduce it is by simply making the vessel bigger, requiring fewer operating cycles and thus a lower replacement rate. Assuming the cost of a vessel and valves, it is fairly easy to predict the annualized cost of ash removal as a function of the useful life of valves, in terms of operating cycles. 
TABLE 3

OPERATING ECONOMICS OF A CONVENTIONAL LOCKHOPPER SYSTEM

Design Basis: Coal feed hopper of the GFETC gasifier, modified by cooling jacket and high performance vaives from Table 2 Operating Data

Operating cycle time

Plant throughput

Effective hopper capacity

Approx. operating cycles in 1982

Cycles per year for single hopper handling

full annual throughput, If plant were operated for 50 weeks per year at same hourly throughput

Extension to Ash Lockhopper of Same Capacity

ASSUMED range of knife gate's useful life between replacements, roughly same as

for flapper valve data from Table 1

Estimated cost, of vessel of same design, with cooling jacket added (only long-term capital item in system)

Annualized capital cost, 5 years at $10 \%$

Best-Case Scenario, Assuming Knife-Gate

Valves Replaced at Rate of Flapper Valves

in Gasifier Service (Table 1), and Single Ball Valve (Table 2) Replaced Annually

BOTH knife-gate valve replacements per year, with useful life of 4,000 and 6,000 cycles

Knife-gate replacement costs, assuming cost of $\$ 10,000$ each

Total annual cost, assuming annual replacement costs from Table 2, plus cost of vessel

Least expensive valves o $\$ 30,000$

Most expensive valves o $\$ 67,000$

Outside range, rounded off, $+\$ 4,000$

for capital cost of vessel

Corresponding cost per ton, based on $0.85 \mathrm{ton} / \mathrm{hr}$ for 50 weeks/year
40 minutes

$0.85 \mathrm{ton} / \mathrm{hr}$

0.57 ton

581 cycles

13,048 cycles

4,000 to 6,000 cycles

$\$ 15,000$

$\$ 3,957 / y r$

6.52 to $4.35 / \mathrm{yr}$

$\$ 130,482$ to $\$ 86,988 / \mathrm{yr}$

$\$ 164,439$ to $\$ 120,945 / \mathrm{yr}$

$\$ 201,439$ to $\$ 157,945 / \mathrm{yr}$

$\$ 120,000$ to $\$ 200,000 / \mathrm{yr}$

$\$ 16.81$ to $\$ 28.01 /$ ton 
Such a preliminary optimization is summarized in figure 3 . The cost per ton of ash removed is computed for a range of hopper sizes and valve lives ranging from 2,000 to 8,000 cycles. The following assumptions have been made:

a. The cost of a pressure vessel varies in decreasing proportion to capacity, other design specifications being equal. Here we have assumed a six-tenths cost escalation factor. The base cost of a feed hopper vessel as shown in Figure 2, plus jacket, is $\$ 13,000$, based on a 1989 quote from the same vessel manufacturer, rounded off upward. Here a base case assume: in capacity of half a ton, with a proce:is throughput of a ton per hour. Fortunately, vessel cost is a relatively minor contribution to the cost per ton of ash passed, within the range of practicality, so that fairly sloppy vessel cost estimation is tolerable. The $\$ 13,000$ includes a cooling jacket, which may not be needed, especially if the ash is partially cooled in a collection boot on the discharge leg of the PFBC.

b. The vessel is assumed to have a useful life of only five years and is financed over that time at an interest rate of 10 percent. If the vessel replacement cost can be stretched over more than five years, which is probable, the sensitivity to valve costs will be even greater.

c. Control systems are not yet well-defined, but are assumed to be roughly comparable for both the lockhopper and gravel bucket alternatives and, therefore, outside the scope of this comparison. In either case, instrumentation items will be long-term capital investments. Similarly, the cost of structural support, purge and vent piping, and connection to the PFBC system is assumed to be common to both alternatives and, therefore, is not included in this comparison.

The maximum cost in the array of Figure 3 is consistent with the single data set of Table 3 . Clearly, much economy can be achieved by increasing vessel size, thus reducing the required operating cycles of valves. For knife gates with a useful life of only 2,000 cycles, greatly increasing the vessel size will significantly reduce the effective operating cost per ton passed. For increasing valve lives, increasing the vessel size has less effect and will eventually actually increase the operating cost. By increasing the volume of the base case vessel (Table 2), with a very durable knife gate that lasts through 8,000 cycles, the operating cost can be reduced to $\$ 5.28 /$ ton of ash passed. This figure is still high, compared with the hypothetical maximum of $\$ 2.61 /$ ton at DGC, from Note 8 of Table 1 .

Given the mathematical model to generate operating cost surfaces as in Figure 3 , we can now vary other parameters to observe the effect on the magnitude and location of the minimum cost per throughput point. Increasing the ash throughput capacity, for closer comparison with the gravel bucket system below, is best achieved by simply increasing the throughput, and the model will determine a locus of optimum vessel capacities to minimize cost for the input range of useful life data. This has been done, in the first data block of Table 4, covering a range of throughputs, for comparison with the 


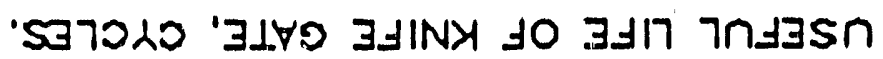

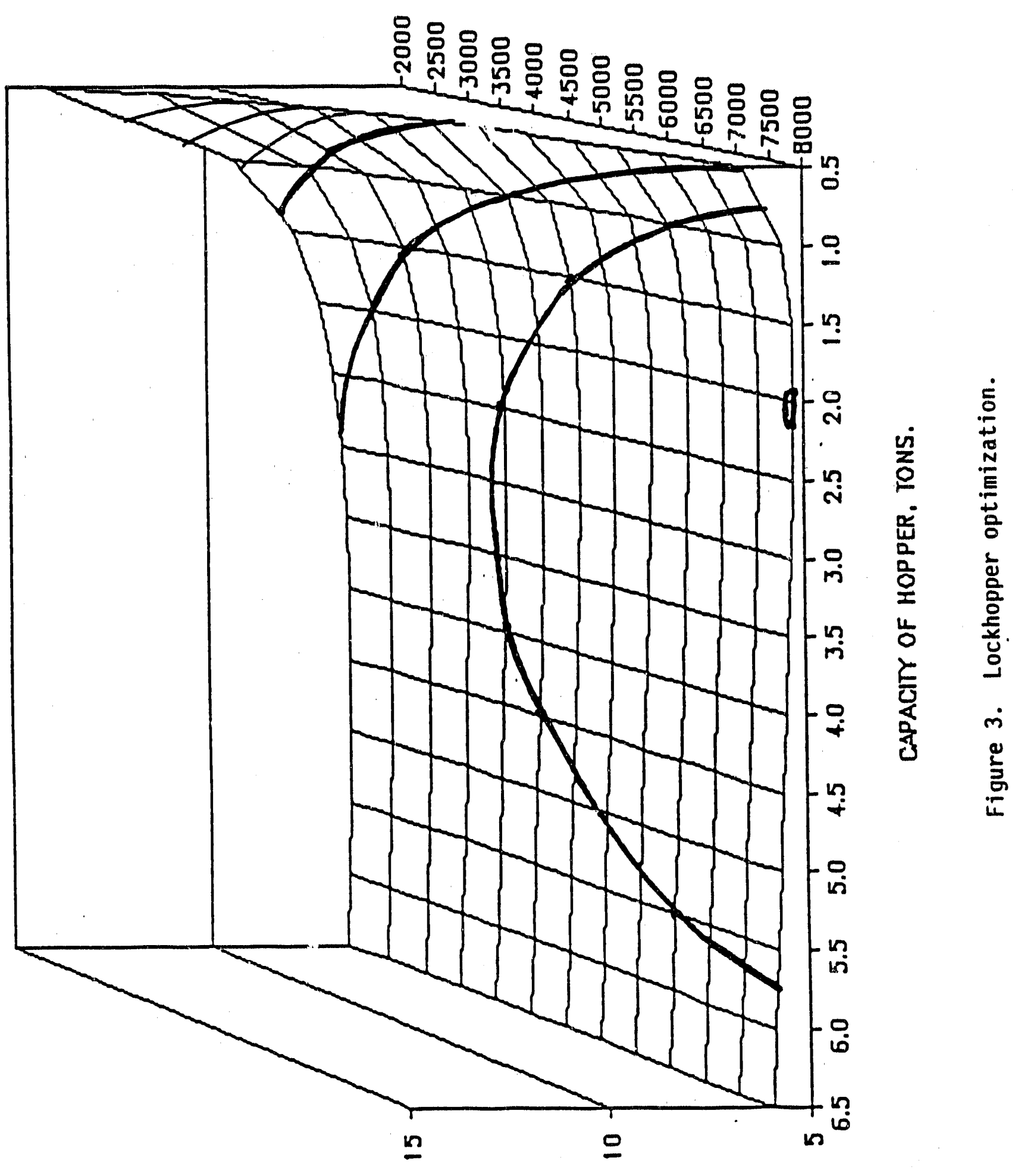

'NOL/\$ OJSSFd HSF JO LSOO 
Variation of operating cost with increasing throughput, 1 ball valve at $\$ 30,000$ (annual7y) and knife gates at $\$ 10,000$

\begin{tabular}{ccc}
$\begin{array}{c}\text { Ash Throughput, } \\
\text { tons/hr }\end{array}$ & $\begin{array}{c}\text { Operating } \\
\text { Cost. S/ton }\end{array}$ & $\begin{array}{c}\text { Optimum V } \\
\text { Capacity. }\end{array}$ \\
\cline { 2 - 4 } & $5.28^{2}$ & 2.0 \\
1.5 & 3.71 & 2.5 \\
$2.0^{2}$ & 2.89 & $3.0^{3}$ \\
2.5 & 2.39 & 3.5 \\
3.0 & 2.05 & 4.0 \\
$3.5^{3}$ & 1.61 & 4.8
\end{tabular}

${ }^{3}$ At variable valve life of 8,000 cycles.

${ }^{2}$ Basis of comparison with equivalent gravel bucket system. See expanded details be? ow.

'For comparison with DGC gasifier ash locks.

DGC hopper holds 3 tons and passes 3.46 tons/hr, but through a $12^{\prime \prime}$ valve rather than a $6^{\prime \prime}$ as assumed here.

Optimum vessel size and operating costs versus replaceable valve life for 2 tons/hr ash throughput, from above data set

\begin{tabular}{ccr}
$\begin{array}{c}\text { Variable Valve } \\
\text { Life. cycles }\end{array}$ & $\begin{array}{c}\text { Operating } \\
\text { Cost. S/ton }\end{array}$ & $\begin{array}{c}\text { Optimum } \\
\text { Capacity }\end{array}$ \\
\hline 2,000 & 3.55 & 6.5 \\
3,000 & 3.38 & 5.5 \\
4,000 & 3.22 & 4.8 \\
$5,000^{4}$ & 3.11 & 4.0 \\
6,000 & 3.02 & 3.8 \\
7,000 & 2.95 & 3.3 \\
8,000 & 2.95 & 3.3
\end{tabular}

"Maximum expected valve life, implied by recent U.S. DOE study (8).

DGC ash hoppers at the Beulah plant and with a hypothetical 2-ton per hour gravel bucket to be discussed. Note that considerable efficiency is achieved at higher throughputs, even with the need for increasing vessel volumes. The cost per throughput ( $\$ /$ ton) is now comparable to that of the DGC hoppers of similar size, which adds to the credibility of this approach. The effect of increasing throughput on the cost surface of Figure 3 is to reduce the overall level and shift the locus of minima to the left, to greater vessel volumes. 
The second data block of Table 4 shows the locus of minima for the input range of useful life data, from 2,000 to 8,000 hours. It must be remembered that the U.S. DOE letdown valve study (8) indicated roughly 5,000 hours as the best that can be expected from even state-of-the-art valves that must seal against high pressures, exposed to hot, abrasive ash. Let us then accept 5,000 hours as the maximum useful 1 ife on a pair of knife gates or any comparable device that can be found for $\$ 10,000$. Under this assumption, the BEST-CASE design for a 2-ton per hour ash lockhopper will require a vessel of 4-ton capacity and have an operating cost of \$3.1I per ton of ash passed.

Tho reakest links in the rationale for the above result are (a) that a semiprotected ball valve, costing $\$ 30,000$ (Table 2) may last for a full year, or around 13,000 cycles; and (b) that a knife gate, or any other kind of valve that achieves the above 5,000-hour limit can be found for $\$ 10,000$. These conditions may be achievable, but are not supported by any hard data discovered in the course of this study. Therefore, taking the limitations of Table 2 and the U.S. DOE valve study quite literaliy, let us assume then that no valve costing less than $\$ 30,000$ is acceptable and that no valve can have a useful life of more than 5,000 hours. Again entering the mathematical model, we assume that all three valves, of whatever design--ball or knife gate--are variable replacement items, at $\$ 30,000$ each, rather than annual replacements. In Figure 4 , the resulting operating costs are extracted for useful valve lives of 3,000 and 5,000 hours. As before, cost is minimized by simply increasing the hopper capacity, although in this case the minimum point appears far off scale and approached asymptotically. Assuming the useful life of 5,000 hours, Figure 4 defines an approximate near-worst case design, wherein the operating cost will be on the order of $\$ 3.00$ to $\$ 4.00$ per ton of ash removed, requiring a vessel of over 12-ton capacity.

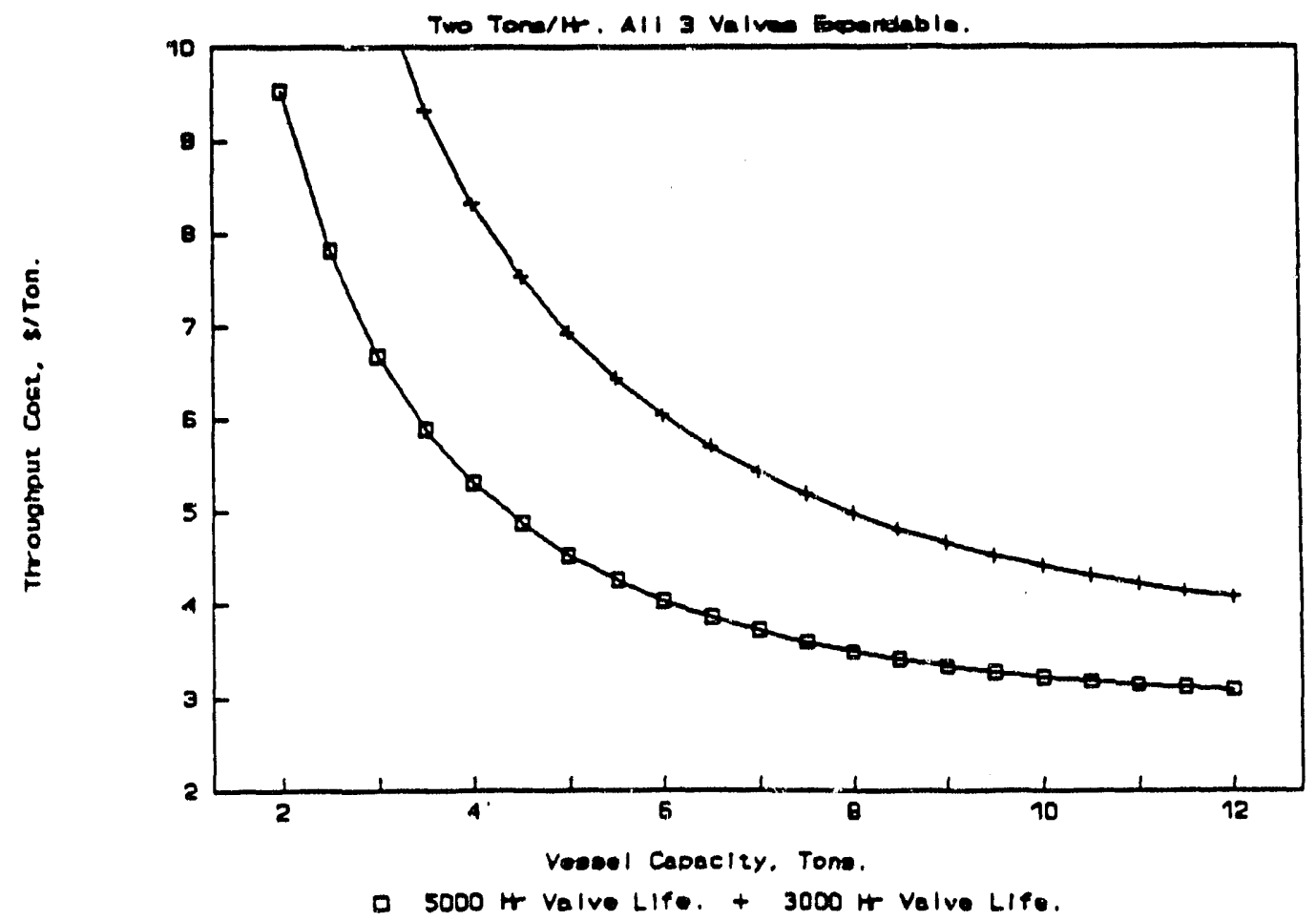

Figure 4. Worst-case lockhopper design. 
The fairly minor difference from the "best" case above is attributed to the economy of scale, in which the far bigger vessel reduces valve wear enough to account for the far more costly valves. Finding space for such a vessel under the PFBC would probably prove a major structural problem, beyond the scope of this study. If valves other than the cheapest in Table 2 are required, the cost will increase proportionately. If valve failures occur at significantly less than 5,000 cycles, or if the economics of overall plant structural design require a smaller lockhopper, the above "worst" case could become far worse jet.

\subsection{GRAVEL BUCKET DESIGN ASSUMPTIONS}

By way of review (1), the most probable, single-chamber gravel bucket design is shown in Figure 5, complete with instrumentation. The tapered vessel is suggested to reduce the possibility of bridging when the supported or reverse fluidized bed should collapse freely. The instrumentation includes multiple fail-safe provisions. Instrumentation is not included in the cost estimates for either the gravel bucket or the comparable lockhopper above, on the rationale that the complexity and cost of instrumentation finally determined essential for a reliable, commercial operation, will be roughly comparable in both cases. Figure 6 shows a multiple-chamber gravel bucket concept; which represents a worse case, since it contains a greater number of valves and, therefore, greater initial capital cost. The possible, though not demonstrated, advantage of the multiple-chamber design is that the relatively short bed in each chamber is more likely to collapse when plugged than a single, taller bed. The 4" diameter research unit, available for fol?ow-on development, is also of a multichamber design, to allow greater versatility in bed configuration.

As a base case for the following cost estimate, a gravel bucket of the general design of Figure 5 has been assumed, with the following assumptions:

a. The ash flow rate will be 2 tons/hr, which corresponds to a 50-MW PFB boiler module at $40 \%$ overall efficiency, using an arbitrarily selected coal of $10,000 \mathrm{Btu} / \mathrm{lb}$ and $10 \%$ ash.

b. The ash will be carried through a gravel bucket at a solids loading of $70 \%$ ash in a mixture of combustion air and product gases cooled to $500^{\circ} \mathrm{F}$. This will constitute a worse-than-best case, as operating cost will prove very sensitive to solids loading, which can be as great as $80 \%$, according to experimental data (5).

c. The maximum packing size range will be $3 / 4$ " to $1 / 4$ ", requiring a diameter possibly as small as 4 inches to maintain operation at the minimum entrainment velocity of the largest particles, which is roughly 8 to $10 \mathrm{ft} / \mathrm{sec}$ at $500^{\circ} \mathrm{F}$ and $150 \mathrm{psig}$. This will require a bed depth of 16 feet to provide a pressure drop of $139 \mathrm{psig}$. For estimating purposes, a ?arger diameter vessel was assumed. The vessel assumed is 20 . feet tall, with a top diameter of 6 inches, expanding to 12 inches at the bottom. Though oversized, according to ?imited experimental data $(1,2)$, these dimensions are submitted as an economic worst case for comparison with the lockhopper. 


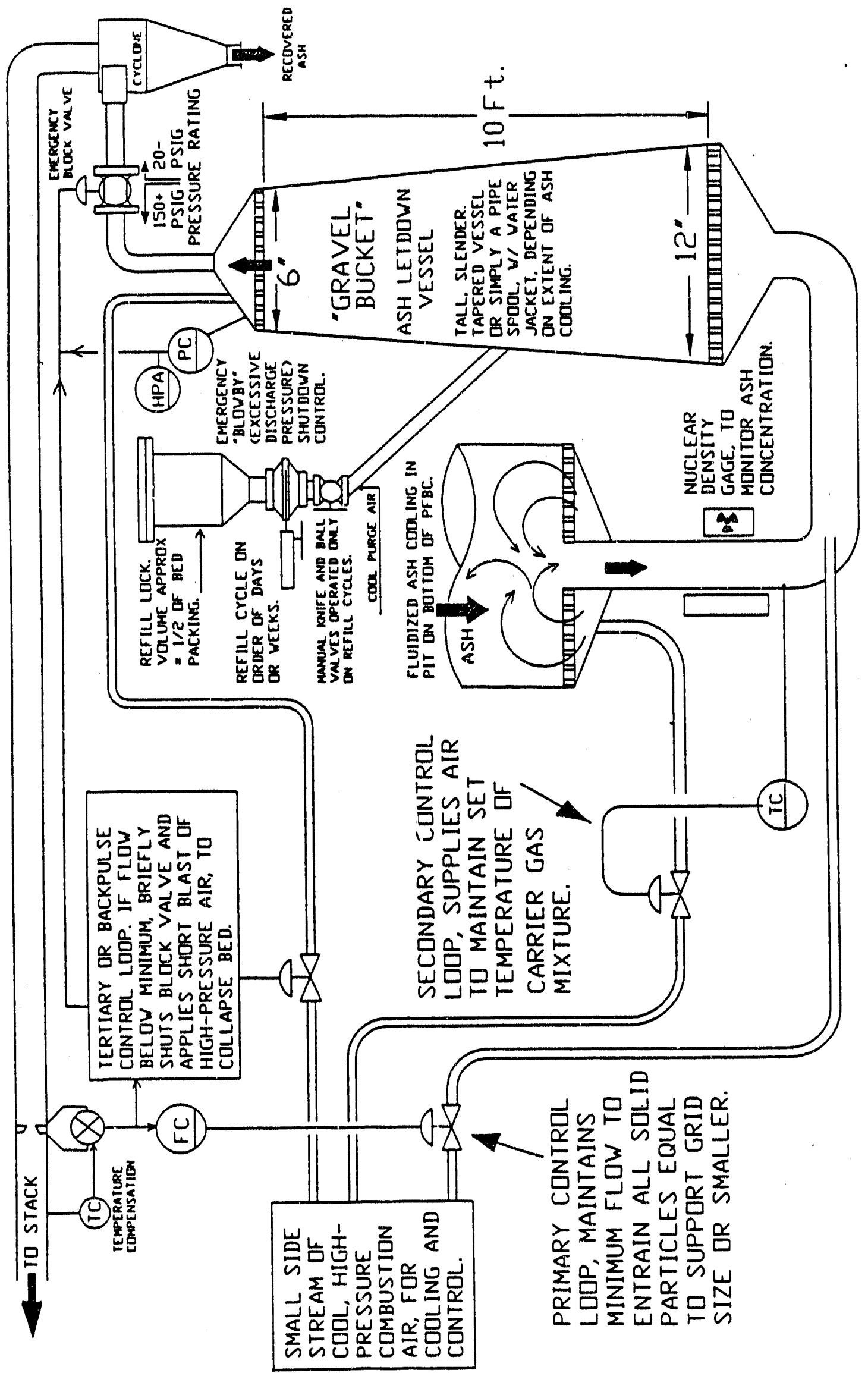

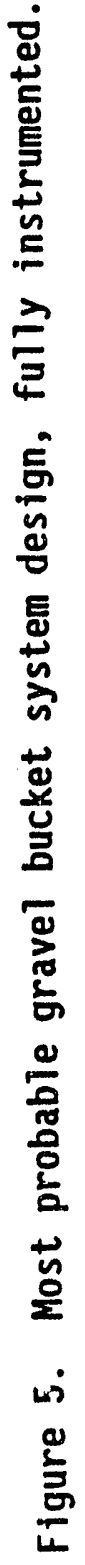




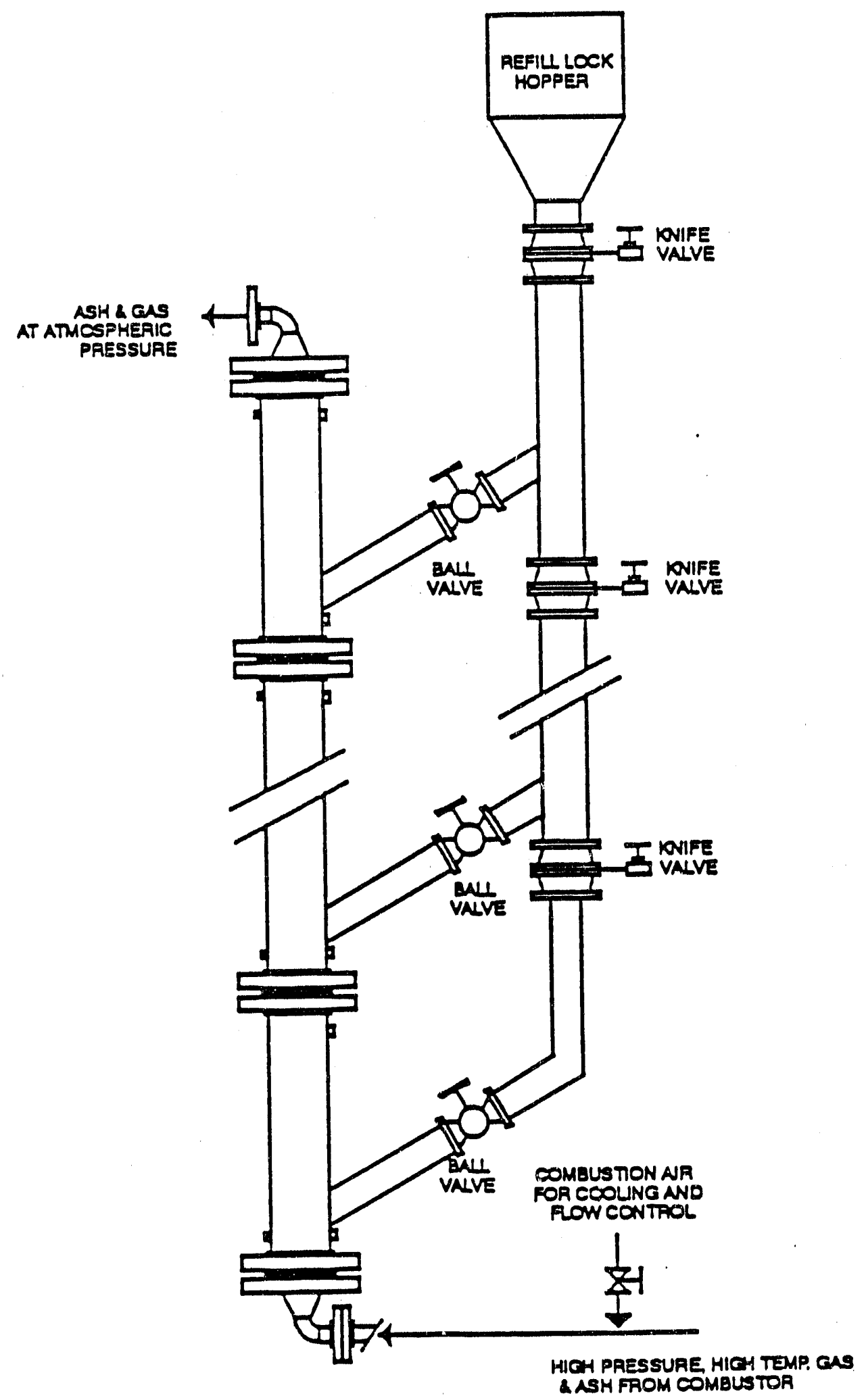

Figure 6. Worst-case, multiple-chamber gravel bucket. 
d. The packed bed will consist of a single, undivided chamber.

Multiple chambers, while potentially desirable, may be prohibitively expensive. On a large scale, the upwardly tapered vessel of Figure 5 is submitted as a means of avoiding the possibility of bridging, to ensure free, reverse fluidization. This assumption is based on experience with a fixed-bed gasifier with a high height-to-diameter ratio (7) and laboratory data relating wall shear to the structural properties of packed beds. Further rationale for this variation in cross section is that, because of the decreasing gas density, an increasing vertical velocity will be needed to maintain the same degree of fluidization.

e. The packing replacement valves will probably be used in loading cycles of several days or weeks, as compared with the roughly hourly cycles of the conventional lockhopper. The pressure sealing valve is assumed to be a ball or piug valve, similar to those assumed for the worst-case lockhopper, again assuming the same useful life of 5,000 cycles. Because it will not be exposed to very high temperatures and fine ash, exotic alloys and exacting specifications will not be required. Therefore, the cost of this valve is assumed to be about half, or $\$ 15,000$. In the base-case calculations, 5,000 is substantially greater than the number of cycles required during the assumed 5-year useful life, so that this item is thus treated as a capital item. The identical valve in the overhead gas line of Figure 5 is for emergency shutdown only and is also treated as a long-term capital item.

f. The cost of the gravel bucket vessel itself is basect on estimates by EERC shop personnel to build it from sections of $6^{n}$ to $12^{n}$. Schedule 80 steel pipe, connected by welded reducers, to approximate the tapered design of Figure 5, plus a water jacket. The gravel replacement hopper is assumed to be a section of $12^{\text {" }}$ pipe, sealed with a biind flange at the top, removed manually for reloading.

g. Within the present degree of uncertainty, the periodic cost of crushed rock for the system of Figure 5 is assumed to be $\$ 20 /$ ton, allowing for some special handling and careful sizing. As is demonstrated, however, rock replacement cost is an insignificant factor in the total cost.

Derivation of a base-case gravel bucket operating cost of $\$ 2.67 /$ ton is shown in Table 5. The economic advantage over lockhoppers, in terms of valve replacements avoided, is partially canceled by the high cost of compression or carrier air. It is assumed that this air will be provided as additional capacity by the compressors providing combustion air to the PFBC and will be independent of whether it is in the form of drawn-down combustion gases or cool air, supplied as indicated in Figure 5. Compressor efficiencies and the cost of electricity to drive them are well beyond the scope of this study, but very familiar to designers of a PFBC power plant.

Comparing the base case of Table 5 with the above best-case lockhopper design, the gravel bucket achieves a savings of only $\$ 0.33 /$ ton, or $\$ 5,000$ per year for the conditions shown. If, however, the same model is repeated, with 
a solids loading of $80 \%$, this cost and savings become $\$ 1.94 /$ ton and $\$ 18,000 /$ year, respectively. Then, if the combined efficiencies of compression (adiabatic pius mechanical) are increased from $63 \%(70 \% \times 90 \%)$ to $70 \%$, these results improve further to $\$ 1.16 /$ ton and $\$ 20,000 /$ year, respectively. Finally, keeping the base-case gravel bucket cost of Table 5, if the equivalent lockhopper costs rise to $\$ 4.00$ and $\$ 5.00 /$ ton--which is quite possible if valve replacements are slightly more frequent than predicted--the resulting savings from use of the gravel bucket rise to $\$ 22,000$ and $\$ 39,000$, respectiveiy. Note that in Tabie 5, the cost of air compression accounts for $66 \%$ of the total base-case cost, so that the uncertainty of capital cost estimation is not critical, and the cost of rock replacement could be completely ignored.

To better visualize the sensitivity to compression costs, consider Figure 7, in which the operating cost per ton is plotted against the solids loading and against a cost factor. The latter is defined as Ce/EaEm, where Ce is the cost of electricity, \$/KWhr, and Ea and Em are the adiabatic and mechanical efficiencies, in $\%$, of che compressor and its driver. The resulting units--multiplied by a million--are, in effect, the compression power cost, in cents per kwhr, adjusted for the inefficiency of conversion to break horsepower. For the base case, this parameter is $\$ 0.0000055 / \mathrm{kWhr}$, or 5.5 adjusted cents/kWhr. This parameter thus includes the operating variables that would be determined by the design of a PFBC power plant. The solids loading is thus the most critical variable in the final design of a gravel bucket and the means of conveying the ash out of the PFBC. The cost surface of Figure 7 has been cut off at \$3.00/ton, as the target level for comparison with best-case lockhoppers. Lower costs may be achieved even at solids loadings as low as about $50 \%$, but only if the cost factor can be kept to around four or lower. Conversely, higher cost factors can be tolerated if solids loading is maintained around its theoretical maximum of $80 \%$.

\subsection{CONCLUSIONS}

The best-case cost of a lockhopper system to remove two tons/hour of ash from a PFBC system is a minimum of $\$ 3.00 /$ ton. This requires the use of valves that (a) are cheaper than the cheapest but still very costly - vaives quoted by vendors for these service conditions, or that (b) valves last longer between replacenient than the 5,000 cycles implied possible by a U.S. DOE study, or that (c) extremely large lockhopper vessels--around 12 tons capacity--be used under the PFBC, which may impose structural limitations. Smaller vessels, assumed valve costs as quoted, or more cautious estimates of useful valve life can easily add whole dollars to the $\$ 3.00 /$ ton optimum.

A less-than-best case gravel bucket design for the same application can offer ash removal for $\$ 2.67 /$ ton, for a minimal cost advantage of $\$ 5,000 /$ year over the equivalent lockhopper. If the solids loading, or ash in carrier air through the gravel bucket, is increased from $70 \%$ to the $80 \%$ indicated possible by cold simulation tests, the operating cost drops to $\$ 1.94 /$ ton, for a saving of $\$ 18,000 /$ year. 
TABLE 5

ECONOMICS OF A GRAVEL BUCKET ASH LETDOWN SYSTEM

\begin{tabular}{|c|c|c|}
\hline $\begin{array}{l}\quad \text { Crushed Rock Replacement Costs } \\
\text { Assumed vessel capacity } \\
\text { At-rest packing density } \\
\text { Percent filled } \\
\text { Vessel capacity, by wt } \\
\text { Rate of bed loss by abrasion } \\
\text { Hours per bed replacement } \\
\text { Annual packing consumption ( } 350 \text { days/yr) } \\
\text { Cost of crushed rock for packing } \\
\text { Annual cost of crushed rock } \\
\text { Valve cycles per 5-year capital life }\end{array}$ & $\begin{array}{l}10 \mathrm{ft}^{3} \\
150 \mathrm{lb} / \mathrm{ft}^{3} \\
70 \% \\
0.26 \text { tons } \\
0.5 \% / \mathrm{hr} \\
200 \mathrm{hrs} \\
11 \text { tons } / \mathrm{yr} \\
\$ 20 / \text { ton } \\
\$ 221 / \mathrm{yr} \\
210 \text { cycles }\end{array}$ & $\begin{array}{l}\% \text { of Total } \\
\text { Annual cost }\end{array}$ \\
\hline $\begin{array}{l}\text { Compressed Air Costs } \\
\text { Assumed solids loading* } \\
\text { Compressed air requirement, weight } \\
\text { Assumed temperature of carrier air } \\
\text { Assumed supply pressure of carrier air } \\
\text { Compressed air requirement, volume } \\
\text { Extra capacity needed for combustion air supply } \\
\text { Assumed adiabatic efficiency* } \\
\text { Calculated break horsepower required } \\
\text { Assumed compressor/driver efficiency } \\
\text { Compressor power requirement } \\
\text { Assumed power cost (Ref. 9) } \\
\text { Annual cost of compressor power }\end{array}$ & $\begin{array}{l}70 \% \\
1714 \mathrm{lbs} / \mathrm{hr} \\
500^{\circ} \mathrm{F} \\
150 \mathrm{psi} \\
381 \mathrm{scfm} \\
90 \% \% \\
95 \mathrm{hp} \\
70 \% \\
101 \mathrm{~kW} \\
\$ 0.035 / \mathrm{kWhr} \\
\$ 29,669 / \mathrm{yr}\end{array}$ & $66 \%$ \\
\hline $\begin{array}{l}\text { Capital Costs } \\
\text { Vessel fabrication (1989 estimate by EERC } \\
\text { Machine Shop, doubled for escalation } \\
\text { and contingency) } \\
\text { Assume rock hopper, chutes, and misc. piping } \\
\text { approx. - cost of main vessel }\end{array}$ & $\$ 11,000$ & \\
\hline $\begin{array}{l}\text { Assume ball valve for ambient temperature } \\
\text { approx. }=1 / 2 \text { cost of cheapest in Table } 2 \\
\text { Emergency shutdown ball valve above vessel } \\
\text { Assume cheap knife gate to protect ball valve } \\
\text { TOTAL CAPITAL COST: } \\
\text { Assumed useful life (same as lockhopper) } \\
\text { Assumed interest rate } \\
\text { Annualized capital cost } \\
\text { TOTAL ANNUAL COSTS: } \\
\text { Average cost per ton of ash passed }\end{array}$ & $\begin{array}{l}\$ 15,000 \\
\$ 15,000 \\
\$ 5,000 \\
\$ 57,000 \\
5 \text { years } \\
10 \% \\
\$ 15,036 / \mathrm{yr} \\
\$ 44,926 / \mathrm{yr} \\
\$ 2.67 / \text { ton }\end{array}$ & $\frac{33 \%}{100 \%}$ \\
\hline $\begin{array}{l}\text { Conventional lockhopper Costs, for Comparison } \\
\text { Assumed best case, from text } \\
\text { Advantage offered by gravel bucket, per ton } \\
\text { Approximate annual savings }\end{array}$ & $\begin{array}{l}\$ 3.00 / \text { ton } \\
\$ 0.33 / \text { ton } \\
\$ 5,000 / y r\end{array}$ & \\
\hline
\end{tabular}

* Most sensitive cost factors, dependent on optimization of means of ash discharge from PFBC system and on optimum compressor design and selection. See sensitivity analysis. 


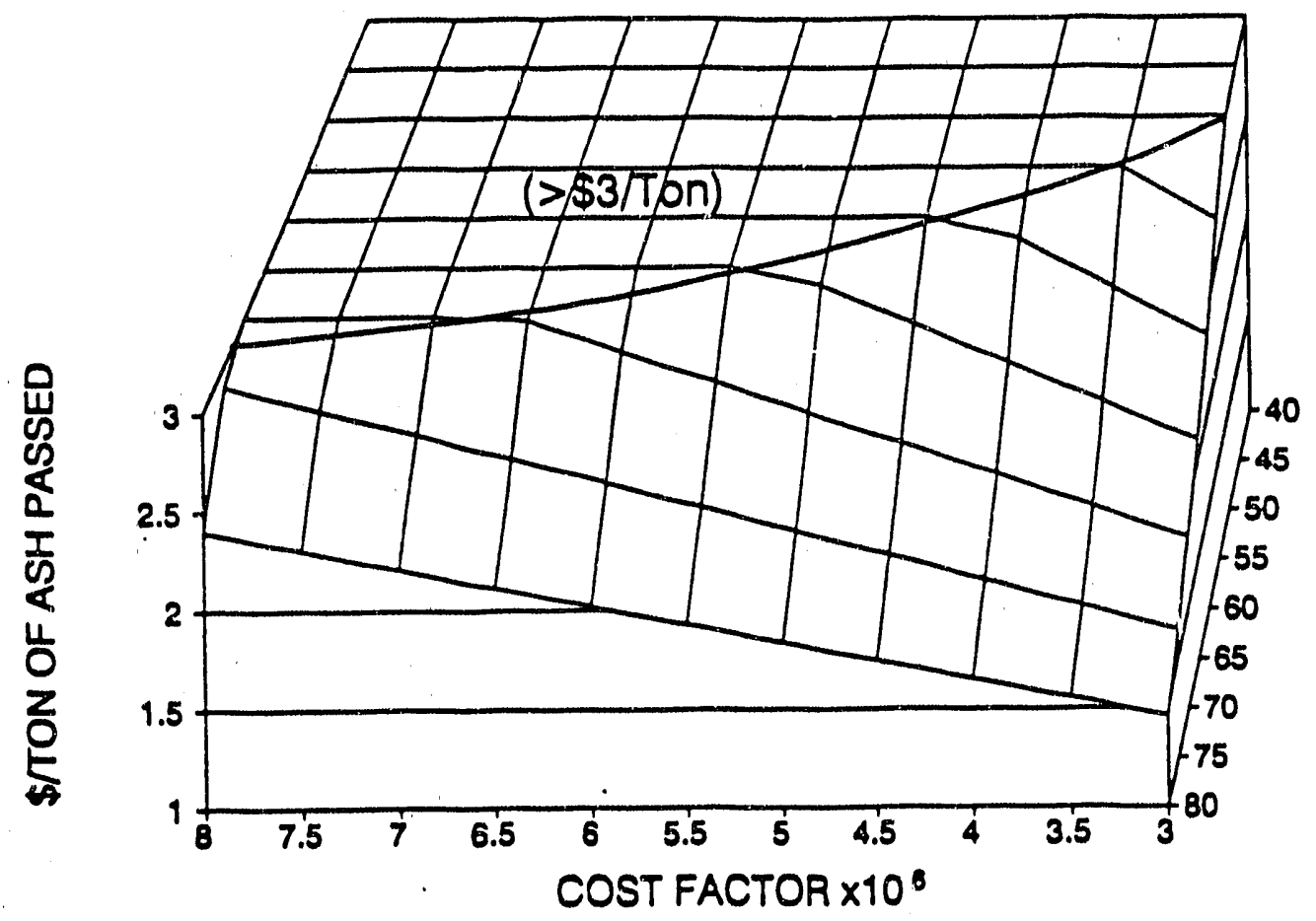

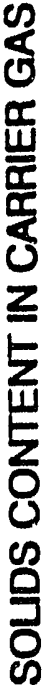

Figure 7. Gravel bucket optimizarion.

One of two major constraints in estimating credible, best-case lockhopper costs is uncertainty as to how far quoted valve costs would be reduced for a fully commercial, replacement parts market in a PFBC power industry. This cost factor should be worked out in discussions of long-term supply economics between potential PFBC power plant operators and valve designers committed to the long-term supply market. The other major constraint is uncertainty as to how far the useful life of valves can be extended by air purge protection, nonsealing knife gates in series, or other design details beyond the scope of this study.

One of two major cost variables in the economics of a gravel bucket system is the cost of compression of additional carrier air. This is, however, easily within the normal scope of designing the PFBC power plant. The other major cost variable is the solids content of ash in the air through the gravel bucket, which must be maximized, approaching the $80 \%$ observed in cold simulation tests, to realize the economic benefirs of this approach to ash removal.

To establish the solids loadings possible, under real-world conditions, will require extended testing in a big, continuous, demonstration-scale PFBC system, so that design modifications can be made as needed between tests, covering a range of gravel bucket design parameters. Doing this in an operating demonstration plant is essential, so that such a test program will not carry the major cost of real or simulated PFBC operation. A gravel bucket test unit, of 4-inch diameter by 10 feet tall, designed for high temperatures at 150 psig, is available at EERC. 
Within the ranges of operating costs, \$/ton of ash passed, and based in the data available to this study, the best cases for lockhoppers overlap slightly with the worst cases for a gravel bucket, indicating that gravel buckets may offer substantial savings over the use of lockhoppers. Further serious developmental efforts to demonstrate gravel bucket operation should be undertaken.

\subsection{REFERENCES}

1. Hendersoi, A.K.; Hauserman, W.B. "Valveless Ass Removal from Pressurized Fluidized-Bed Combustion Systems by Gravel Bucket," Final Technical Project Report for the period July 1 through June 30, 1990, U.S. DOE Contract No. DE-AC21-86MC25151, November 1990.

2. Hauserman, W.B.; Henderson, A.K. "Valveless Ash Removal from Pressurized Fluidized-Bed Combustion Systems," ASME Energy-Sources Technology Conference and Exhibition, New Orleans, LA, Jan. 14-18, 1990.

3. Hauserman, W.B.; Johnson, M.D. "Use of Cheap, Sacrificial Materials for Vaive Trim in Erosive Slurry Applications," Final Report, U.S. DOE Contract No. DE-AC21-85MC22109, Apri1 1987.

4. Daws, S.G. "General Components Experience in the Grimthorpe Plant During Test Series A2," British Coal/CEGB PFBC Program, 1989.

5. Towers, T.G.; Lukes, A.C. of Dakota Gasification Company, Beulah, ND, personal communication, 1986-1990.

6. Hauserman, W.B. "Hardness of Fine Ground Coals and Mineral Residues to Predict Siurry Erosion," Journal of Powder Technology 1984, 43.

7. Hauserman, W.B.; Willson, W.G. Mechanical Problems in the Design of a Fixed-Bed, Slagging Gasifier," ASME, Energy-Sources Technology Conference \& Exhibition, Jan. 30-Feb. 2, 1983, Houston, TX.

8. Ayers, W.J.; Wojewodka, R.A. "The State-of-the-Art Lockhopper VaTve Testing and Development Program: Final Report," DOE/WETC-85/2001, January 1985.

9. Electric Power Research Institute. "TAG - Technical Assessment Guide, Vols. 1 and 3," EPRI P-4463-SR, 1986. 

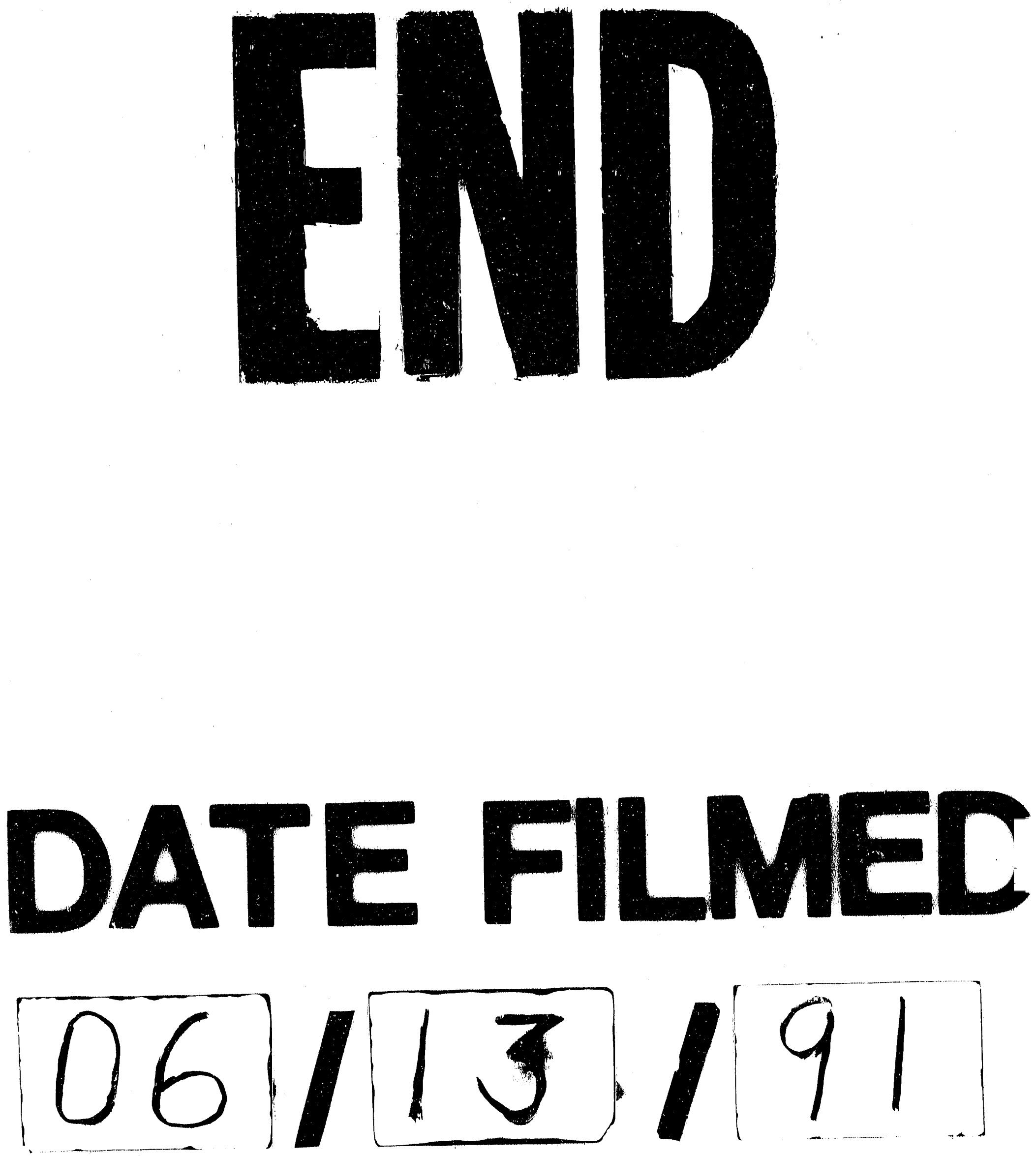
